\title{
IL-15 Signaling in Skeletal Muscle: Implications in Modulation of PGC-1alpha and Mitochondrial Biogenesis
}

Grant C. O'Connell

Follow this and additional works at: https://researchrepository.wvu.edu/etd

\section{Recommended Citation}

O'Connell, Grant C., "IL-15 Signaling in Skeletal Muscle: Implications in Modulation of PGC-1alpha and Mitochondrial Biogenesis" (2014). Graduate Theses, Dissertations, and Problem Reports. 6337.

https://researchrepository.wvu.edu/etd/6337

This Thesis is protected by copyright and/or related rights. It has been brought to you by the The Research Repository @ WVU with permission from the rights-holder(s). You are free to use this Thesis in any way that is permitted by the copyright and related rights legislation that applies to your use. For other uses you must obtain permission from the rights-holder(s) directly, unless additional rights are indicated by a Creative Commons license in the record and/ or on the work itself. This Thesis has been accepted for inclusion in WVU Graduate Theses, Dissertations, and Problem Reports collection by an authorized administrator of The Research Repository @ WVU. For more information, please contact researchrepository@mail.wvu.edu. 


\title{
IL-15 Signaling in Skeletal Muscle: Implications in Modulation of PGC-1 $\alpha$ and Mitochondrial Biogenesis
}

\section{Grant C. O'Connell}

\author{
Thesis submitted \\ to the School of Medicine \\ at West Virginia University \\ in partial fulfillment of the requirements for the degree of \\ Master of Science in \\ Exercise Physiology
}

\author{
Emidio E. Pistilli, Ph.D., Chair \\ Stephen E. Alway, Ph.D. \\ John M. Hollander, Ph.D. \\ Division of Exercise Physiology
}

\author{
Morgantown, West Virginia \\ 2014
}

Keywords: Interleukin-15, Interleukin-15 Receptor Alpha, Skeletal Muscle, Mitochondria, PGC-1a, PPARd

Copyright 2014 Grant C. O'Connell 


\title{
ABSTRACT \\ IL-15 Signaling in Skeletal Muscle: Implications in Modulation of PGC-1 $\alpha$ and Mitochondrial Biogenesis
}

\author{
Grant C. O'Connell
}

Altering interleukin-15 (IL-15) signaling through ablation of interleukin receptor alpha (IL$15 \mathrm{R} \alpha$ ) in the IL-15R $\alpha$ global KO mouse has been shown to result in an oxidative shift in skeletal muscle characterized by enhanced fatigue resistance and increases in mitochondrial density. However, the mechanism of this phenomenon is unclear, as IL-15 signaling in skeletal muscle has been virtually unexplored. It has been previously suggested that loss of IL-15R $\alpha$ in the global KO mouse directly results in an increase in muscle IL-15 secretion, and this increase in secreted IL-15 acts on skeletal muscle in an autocrine fashion, directly stimulating pro-oxidative remodeling. Thus, the purpose of this study was to examine the effects of muscle IL-15R $\alpha$ loss on the ability of muscle to secrete and respond to IL-15, and also to determine whether IL-15 has the ability to act directly on skeletal muscle to induce pro-oxidative changes. These aims were addressed through the generation of $\mathrm{C}_{2} \mathrm{C}_{12}$ myogenic cell lines lacking IL-15R $\alpha$, as well as a through the development of a novel muscle-specific IL-15R $\alpha$ KO mouse. Myogenic cell cultures lacking IL$15 \mathrm{R} \alpha$ failed to exhibit the capacity to respond to exogenously provided IL-15. Furthermore, IL$15 \mathrm{R} \alpha$-null cultures displayed a depressed ability to secrete IL-15, even in the presence of proinflammatory stress. In support of this observation, mice lacking IL-15R $\alpha$ conditionally in skeletal muscle exhibited no changes in circulating IL-15. However, acute treatment of wild type myogenic cultures with IL-15 resulted in induction of the pro-oxidative genes PGC-1 $\alpha$ and PPAR $\delta$. These results provide evidence that IL-15 has the capacity to act directly on skeletal muscle in a pro-oxidative manner, and that loss of IL-15R $\alpha$ ablates the ability of skeletal muscle to secrete and respond to IL-15. Collectively, these results suggest that the muscle changes observed in the IL-15R $\alpha \mathrm{KO}$ mouse are driven by increased muscle response to IL-15, but that the ability to secrete and respond to IL-15 is enhanced in the global IL-15R $\alpha$ KO mouse due to a confound such as immunodeficiency. 


\section{IL-15 signaling in skeletal muscle: Implications in modulation of PGC-1 a and mitochondrial biogenesis. \\ Grant C O'Connell}

Division of Exercise Physiology, West Virginia University School of Medicine 


\title{
IL-15 signaling in skeletal muscle: Implications in modulation of PGC-1 $\alpha$ and mitochondrial biogenesis.
}

\author{
Grant C O’Connell
}

Division of Exercise Physiology, West Virginia University School of Medicine

Chapter 1: Introduction $\quad 1$

Chapter 2: Background $\quad 4$

2.1 Functional mitochondria are essential in maintaining cellular homeostasis 4

$2.2 \quad$ Mitochondrial dysfunction $\quad 6$

2.3 Mitochondrial biogenesis and PGC-1 $\alpha \quad 7$

2.4 IL-15: A potential novel target in mitochondrial dysfunction $\quad 9$

2.5 Background summary, aims, and hypothesis 14

Chapter 3: Results $\quad 16$

3.1 Generation of stable IL-15Ra KO myoblasts 16

3.2 Effects of chronic IL-15 treatment in the presence and absence of IL-15Ra

3.3 Effects of acute IL-15 treatment on pro-oxidative gene expression 22

3.4 Effects of IL-15Ra loss on IL-15 secretion In-Vitro 23

3.5 Conditional knockout of IL-15Ra in mouse skeletal muscle 24

3.6 Effects of IL-15Ra loss on IL-15 transcription and secretion in vivo 25

$\begin{array}{ll}\text { Chapter 4: Discussion } & 27\end{array}$

Chapter 5: Experimental Procedures

5.1 Animals 33

5.2 Generation of muscle-specific IL-15Ra KO mice 33

5.3 Analysis of IL-15R and IL-15 expression in transgenic mice 34

5.4 Generation of IL-15Ra deficient stable myoblasts 34

5.5 Assessment of stable cell-line growth rates $\quad 35$

5.6 Chronic treatment of myogenic cultures with IL-15 36

5.7 Acute treatment of myogenic cultures with IL-15 36

5.8 Assessment of mitochondrial density 237

5.9 Mitochondrial DNA Content $\quad 37$

5.10 Assessment of myotube morphology 38

5.11 Measuring IL-15 secretion in vitro 38

5.12 IL-15 and IL-15Ra ELISA

5.13 Assessment of total culture protein content 40

5.14 RNA Isolation and RT-PCR $\quad 40$

5.15 Statistical analysis $\quad 41$

Chapter 6: References $\quad 42$

Chapter 7: Supplementary Data 


\title{
IL-15 signaling in skeletal muscle: Implications in modulation of PGC-1a and mitochondrial biogenesis.
}

\author{
Grant C O'Connell
}

Division of Exercise Physiology, West Virginia University School of Medicine

\section{Chapter 1.}

\section{Introduction:}

Proper mitochondrial function is essential in maintaining cellular homeostasis. The mitochondrial network is the primary regulator of cellular metabolism and energy status; disruptions in cellular ATP supply by way of mitochondrial dysfunction severely impairs cell function and as a result plays a central role in the pathogenesis of a wide array of severe neurological, metabolic, and myogenic disorders. Mitochondrial dysfunction, which is characterized by impaired mitochondrial oxidative capacity, has been implicated as a key component in the pathologies of Alzheimer's, Huntington's, Parkinson's, ALS, diabetes, obesity, aging and cancer cachexia. $^{1-6}$ Increasing mitochondrial mass by way of mitochondrial biogenesis in conditions of mitochondrial dysfunction has been shown to improve total cellular oxidative capacity and prevent bioenergetic crisis, thus rescuing cellular function, reducing symptom severity, and improving quality of life..$^{7-14}$ As a result, there has been a recent push for the development of therapies which stimulate mitochondrial biogenesis by targeting peroxisome proliferator-activated receptor gamma coactivator 1-alpha (PGC-1 $\alpha$ ), a transcriptional coactivator which is known to be one the key regulators of mitochondrial replication. Previously published and preliminary data produced by our laboratory using a transgenic mouse model has provided evidence that altering signaling of the cytokine interleukin 15 (IL-15) by global knockout of one of its key regulatory proteins, interleukin 15 receptor alpha (IL-15Ra), results in potent activation of PGC-1 $\alpha$ transcription, significant increases in mitochondrial mass, and improved oxidative capacity in the skeletal muscle of mice. ${ }^{15,16}$ Because it is evident that modulating IL-15 and IL-15Ra can elicit dramatic positive mitochondrial changes, determining the specific nature of the changes and the signaling mechanisms responsible provides potential for the development of therapies targeting $\mathrm{IL}-15$ in disease states involving mitochondrial dysfunction. Unfortunately, it is unclear how loss of IL-15Ra affects IL-15 signaling in skeletal 
muscle, as IL-15 signaling in muscle is relatively uncharacterized. It has been previously suggested that loss of IL-15Ra in the global KO mouse directly results in an enhanced ability of skeletal muscle to secrete IL-15, and that this increase in secreted IL-15 acts on muscle in an autocrine fashion, resulting in the pro-oxidative changes which have been characterized. ${ }^{16,17}$ However, this mechanistic explanation for the exercise and muscle phenotypes in the global IL$15 \mathrm{Ra} \mathrm{KO}$ mouse is complicated by the fact that IL-15Ra is ubiquitously absent, making it difficult to determine whether the effects of $\mathrm{IL}-15 \mathrm{Ra}$ loss in non-muscle tissues contribute to the changes observed in skeletal muscle, or whether these changes are a direct result of IL-15R $\alpha$ loss in muscle tissue alone. In an additional complication, this mechanistic explanation for the changes observed in the IL-15Ra global KO mouse suggests that the action of IL-15 in muscle differs in some aspects from what is observed in the immune system, in which IL-15Ra is essential for the ability of cells to secrete and respond to IL-15. ${ }^{18-22}$

Thus, based on the lack of current knowledge regarding the exact function and mechanism of IL-15 signaling in skeletal muscle, as well as the promising mitochondrial changes observed with loss of IL-15Ra in the global KO mouse, the purpose of this project was to further investigate the previously proposed mechanism for the pro-oxidative muscle changes which have been observed with IL-15Ra loss. Therefore, this project had three specific aims:

\section{Aim 1:}

Determine the effects of muscle-specific IL-15Ra loss on skeletal muscle IL-15 secretion.

\section{Hypothesis 1:}

Loss of IL-15Ra specifically in skeletal muscle increases IL-15 secretion.

\section{Aim 2:}

Determine how loss of IL-15Ra impacts the ability of skeletal muscle to respond to IL-15.

\section{Hypothesis 2:}

Loss of IL-15Ra negatively impacts the ability of skeletal muscle to respond to IL-15, but IL-15 signaling can persist without IL-15Ra in the presence of sufficiently elevated levels of IL-15.

\section{Aim 3:}

Determine whether IL-15 acts directly on skeletal muscle to induce pro-oxidative changes.

\section{Hypothesis 3:}

IL-15 has the capacity to act directly on skeletal muscle in a pro-oxidative manner. 
Aim one was addressed in vitro via the generation of $\mathrm{C}_{2} \mathrm{C}_{12}$ myoblasts lacking IL-15Ra, as well as in-vivo using a conditional muscle specific IL-15Ra mouse model. It was expected that loss of IL-15Ra in both contexts would result in measureable increases in IL-15 secretion. IL-15Ra-null myoblasts were also used to address aim two; it was expected that loss of IL-15R $\alpha$ would negatively impact the ability of myogenic cultures to respond to exogenously provided IL15 , but that IL-15 signaling would be possible at elevated concentrations. The third aim was addressed through the treatment of wild type skeletal muscle cultures with recombinant IL-15. It was expected that IL-15 treatment would result in a similar increase in mitochondrial mass as observed in the IL-15Ra global KO mouse. 


\section{Chapter 2.}

\section{Background:}

\section{1}

Functional mitochondria are essential in maintaining cellular homeostasis:

Adenosine triphosphate (ATP) is nucleoside triphosphate composed of a single adenosine molecule bound to three phosphate groups. In biological systems, hydrolysis of the anhydride bond linking the $\gamma$ and $\beta$ phosphate to form adenosine diphosphate and free phosphate results in the release of free energy. This free energy can be utilized by the cell to do work. A majority of the most critical cellular processes including active membrane transport, intracellular signal transduction, and protein synthesis require ATP as a substrate. Due to the involvement of ATP in such a vast number of cellular processes, ATP is constantly being hydrolyzed, and thus needs to be constantly replenished in order for these cellular processes to continue without interruption.

In most mammalian cell types, the majority of ATP is synthesized by subcellular organelles known as mitochondria via a process known as oxidative phosphorylation (OXPHOS). Mammalian cells contain a vast and fluid mitochondrial network. Mitochondria are characterized by a double membrane structure and are unique in respect to other organelles in that they contain a circular genome distinct from the nuclear genome. Mitochondrial DNA (mtDNA) contains 13 genes which encode for mitochondrial polypeptides which constitute critical subunits in the OXPHOS machinery, as well as 24 genes which produces the transfer RNAs and ribosomal RNAs necessary for mitochondrial protein assembly. While the mitochondria employ a self-contained genome, many of the genes which encode protein essential for mitochondrial assembly and function are located on the nuclear genome. The nuclear genome encodes mitochondrial transcription factor A (TFAM) and mitochondrial DNA polymerase (POLG), which are proteins essential for mitochondrial DNA transcription and replication. The nuclear genome also codes for the remaining OXPHOS proteins, as well numerous structural, enzymatic, and transport proteins. ${ }^{23-25}$ Many of these nuclear genes are under the control of the nuclear respiratory factor (NRF), estrogen-related receptor (ERR), and peroxisome proliferator-activated receptor (PPAR) families of transcription factors ${ }^{26}$ The rate of mitochondrial turnover is high; radioactive isotope pulse chase experiments have shown that mitochondrial half-life may be as short as 1.3 days in highly metabolically active tissues such as 
the liver, and mitochondria are constantly produced and degraded through processes respectively known as mitochondrial fission and mitophagy. ${ }^{27}$

The double membrane mitochondrial structure is essential in terms of role mitochondria play in energy production. Mitochondria are composed of two phospholipid bilayer membranes referred to as the inner mitochondrial and outer mitochondrial membranes, the second of which displaying low ionic permeability. The space between the inner and outer membrane is known as the inter-membrane space and the area within the inner-membrane is known as the mitochondrial matrix. The protein machinery most directly involved in ATP synthesis, the respiratory chain proteins, are located on the inner-membrane. Invaginations of the innermembrane known as cristae provide expanded surface area and increase the capacity to produce ATP. During oxidative phosphorylation, the respiratory chain proteins use hydrogenderived electrons generated through the oxidation of organic acids to reduce oxygen to form water and in the process generate ATP. Oxidation of pyruvate and fatty acids through various metabolic processes such as the beta oxidation and the citric acid cycle (TCA) produces hydrogen bound to the electron carriers flavin adenine dinucleotide (FAD) and nicotinamide adenine dinucleotide (NAD). Electrons derived from FADH2 and $\mathrm{NADH}$ are then passed through the the respiratory chain proteins of the mitochondrial inner-membrane via a series of oxidation and reduction reactions, and in the process move matrix protons across the membrane into the inter-membrane space. The first respiratory chain protein, a trans-inner-membrane protein known as NADH dehydrogenase (Complex 1), binds and oxidizes matrix NADH. The electrons derived from NADH oxidation are used by NADH dehydrogenase to reduce coenzyme $\mathrm{Q}(\mathrm{CoQ})$, a lipid soluble quinone found within the lipid bilayer of the inner-membrane. This transfer of electrons from $\mathrm{NADH}$ to $\mathrm{CoQ}$ through complex 1 results in the movement of protons from the matrix to the inter-membrane space. The trans-inner-membrane protein succinate dehydrogenase (Complex 2) oxidizes succinate to fumarate during the TCA cycle which generates $\mathrm{FADH} 2$. FADH2 is than oxidized by complex two and the transferred electrons are used to reduce CoQ. CoQ reduced by complexes 1 and 2 are oxidized by another trans-innermembrane protein known as cytochrome reductase (Complex 3). Electrons gained by complex 3 via $\mathrm{CoQ}$ oxidation are then used to reduce cytochrome $C$, a heme protein located in the intermembrane space. Movement of electrons from CoQ to cytochrome $\mathrm{C}$ through complex 3 also results in the movement of matrix protons to the inter-membrane space. The transmembrane protein cytochrome $\mathrm{C}$ oxidase (Complex 4) then transfers electrons from reduced to cytochrome $\mathrm{C}$ back to the matrix where they can be used to reduce oxygen, forming water. This final 
electron transfer through complex 4 once again results in proton movement. The cumulative result of the activity of the respiratory chain proteins is a high concentration of protons in the inter-membrane space as opposed to the matrix. ATP synthase is a protein integral to the innermembrane which forms a proton pore. Protons move down their electrochemical gradient through ATP synthase and in the process drive the formation of ATP from ADP and free phosphate. ${ }^{28}$ Interruption of a single step of this complex process can result in dramatically reduced ATP production, thus disrupting cellular energy supply and the ability of the cell to carry out homeostatic processes.

\section{2}

\section{Mitochondrial dysfunction:}

Mitochondrial dysfunction is a general term which can be used to describe situations during which the ability of the mitochondria to produce ATP by way of oxidative phosphorylation is impaired. The bio-energetic crisis that occurs as a result of mitochondrial dysfunction severely impairs cellular function and through several indirect pathways can result in apoptosis. Interruptions in mitochondrial ATP supply severely limit the ability of the cell to carry out many critical ATP-dependent processes. As a result, during states of mitochondrial dysfunction, there is typically a substantial compensatory up-regulation of ATP production by way of anaerobic pathways, which can result in cellular acidification. Cellular acidosis can interfere with many $\mathrm{pH}$ dependent biochemical reactions and further hinder cellular function. ${ }^{29}$ Interruptions in the function of the respiratory chain proteins not only reduces cellular ATP supply and impairs cellular homeostatic function, but in many cases results in the production of mitochondrial reactive oxygen species (ROS), which in turn can trigger mitochondrial-mediated apoptotic pathways as well as place the cell in a state of oxidative stress. ${ }^{30,31}$

During conditions which respiratory chain electron transport is inhibited, there is an increase in mitochondrial matrix ratio of NADH to NAD+. Increases in matrix NADH can lead to electron saturation of the flavin mononuclotide (FMN) group of complex 1. When FMN becomes electron saturated, it readily reacts with oxygen to produce superoxide. ${ }^{32}$ Impaired electron transport ability can also lead to the electron saturation of the CoQ pool. If the ratio of reduced $\mathrm{CoQ}$ to oxidized $\mathrm{CoQ}$ becomes too high, a phenomenon known as reverse electron transport (RET) can occur. During RET, electrons from reduced CoQ are transferred back to the CoQ binding domain of Complex 1. This atypical flow of electrons also produces superoxide, potentially once again through FMN saturation. ${ }^{33}$ While these are only two examples by which 
electron transport interruption produces ROS, many other mechanisms exist, many directly related to electron saturation of the NAD or CoQ pools. ${ }^{30,31}$ Constitutive production of mitochondrial ROS promotes the initiation of pro-apoptotic events such as mitochondrial permeability transition pore opening and cytochrome $\mathrm{C}$ release.$^{34}$ In addition to the initiation of apoptotic signaling cascades, ROS produced in states of impaired respiratory chain function damage the respiratory chain proteins themselves, further exacerbating the situation, resulting in further ROS generation. Excessive ROS also damages mtDNA and can lead to the production of defective mitochondrial proteins. ${ }^{35}$ Due to the host of problems induced by deficits in the ability to produce energy through oxidative pathways, it is not surprising that mitochondrial dysfunction has been identified as key component in the pathologies of several of the most common and severe human conditions ranging from metabolic disorders such as diabetes to neurodegenerative diseases such as Hunginton's, Parkinson's, Alzheimer's, and dementia. ${ }^{1,5,29}$

\section{3}

\section{Mitochondrial biogenesis and PGC-1a: Implications in the treatment of mitochondrial dysfunction:}

Increasing mitochondrial mass in conditions in which there is a respiratory deficit may hold great promise in preventing bioenergetics crisis and rescuing cellular function. Increasing mitochondrial mass by way of mitochondrial biogenesis in has been shown to raise residual oxidative capacity in affected tissues, limit functional impairment, reduce symptom severity, and improve quality of life. Inducing mitochondrial biogenesis has the potential to improve clinical outcome in a wide array of disorders through a variety of mechanisms, primarily through increasing cellular energy supply and decreasing ROS formation. ${ }^{7-13}$ In many conditions involving mitochondrial dysfunction, impaired ability of the mitochondria to produce ATP is thought to play a major role in disease pathology through the homeostatic stress a diminished energy supply can place on cells in the affected tissues. In several of these conditions, defects or deficiencies in the respiratory chain proteins by way of gene mutations results in decreased ATP production. In a condition where there is a $50 \%$ decrease in ATP production per unit of mitochondrial mass, doubling mitochondrial mass holds the potential to return the total amount of ATP produced by the entire mitochondrial population back to healthy levels. While this strategy does not address the underlying cause of the respiratory deficit itself, increasing cellular ATP supply allows more energy for cellular homeostatic function and could improve overall tissue functionality. ${ }^{14}$ This is especially true in conditions caused by heteroplasmic 
mtDNA mutations. The mtDNA mutations that are accrued with aging are a good example. Throughout the life span, oxidative stress and uncorrected replication errors result in mtDNA mutations on a copy by copy basis, not as a populational phenomenon. ${ }^{3}$ Copies of a single mutation will expand through replication but usually will only be carried by a portion of the entire pool of mtDNA. In heteroplasmic conditions, the mutation or mutations most responsible for functional detriments may be only carried by a portion of mitochondrial population while the remaining populating may carry corresponding wild type alleles. Stimulating mitochondrial biogenesis in these cases will result in expansion of the functional wild-type population which in turn could greatly enhance cellular OXPHOS capacity. ${ }^{14}$

Another mechanism by which stimulating mitochondrial biogenesis could be beneficial in conditions of mitochondrial dysfunction is through limiting mitochondrial ROS generation. The ROS generated as a result of mitochondrial dysfunction are thought to play an import role in the progression of several neurodegenerative diseases, especially Alzheimer's, as prolonged oxidative stress can result in impaired cellular function and the initiation of apoptotic signaling cascades. $^{1,36}$ Saturation of the respiratory complexes with electrons during states of low respiratory capacity and high energy demand results in the generation of ROS which in turn can cause damages to the respiratory proteins themselves, further decreasing their functionality, resulting in even greater propensity for ROS production ${ }^{30,31}$. Increasing the turnover of ROS damaged mitochondrial proteins through mitochondrial biogenesis could potentially limit this vicious cycle and depress cellular oxidative stress. ${ }^{11}$

PGC-1 $\alpha$ is a transcriptional co-activator which has been shown to induce the expression of genes known to be essential for mitochondrial biogenesis, modulation of mitochondrial function, and ROS detoxification. ${ }^{26,37}$ PGC-1a has the ability to potently induce increases in mitochondrial mass, ${ }^{38}$ and as a result, is being increasing sighted as a therapeutic target in mitochondrial diseases and conditions which involve mitochondrial dysfunction. ${ }^{14,39}$

In terms of activity, PGC-1 $\alpha$ is regulated at both the translational and post-translational level. PGC-1 $\alpha$ transcription is induced through various stimuli linked to cellular metabolism and energy status. PPARs are a family of ligand-induced transcription factors activated by various eicosanoids and fatty acids and were some of the first transcription factors shown to induce PGC-1a gene expression. ${ }^{40}$ PGC-1a expression under the CREB and MEF2 transcriptions factors is also initiated by AMPK, ${ }^{41,42}$ one of the master sensors of cellular energy status, by calcineurin and various CAMKs, ${ }^{43}$ which are sensitive to cellular calcium load, as well as by 
cAMP dependent pathways, ${ }^{44}$ which are sensitive to cellular glucose metabolism. PGC-1 $\alpha$ expression is also induced by increases in ROS, oxygen, and nitric oxide through a variety of mechanisms. ${ }^{37}$ Expectedly, exercise strongly stimulates PGC-1 $\alpha$ gene expression and a myriad of the adaptations that occur with exercise are believed to be a result of PGC-1 $\alpha$ activity. ${ }^{45}$

Some of the same factors that are responsible for initiating PGC-1 $\alpha$ transcription are also responsible for its post-translational activation. PGC-1a has a relatively limited half-life; phosphorylation of a series of tyrosine and serine residues by substrates such as AMPK and p38 MAPK have been shown to significantly stabilize the protein. ${ }^{46,47}$ One of the most documented post-translational modifications shown to be essential for PGC-1 $\alpha$ activity is deacetylation of several acetylation sites between amino acids 200 and 400 by Sirt1, a class 3 histone/protein deacetylase whose activity requires NAD as a cofactor, again strongly linking PGC-1 $\alpha$ activity to cellular energy status. ${ }^{48}$ Once post-translationally active, PGC-1a can bind and enhance the activity of several transcription factors that regulate genes associated with mitochondrial biogenesis and function. Cofactors activated by PGC-1 $\alpha$ include multiple members of the PPAR family, NRF1, NRF2, as well as EER family members. ${ }^{26}$ In addition to the

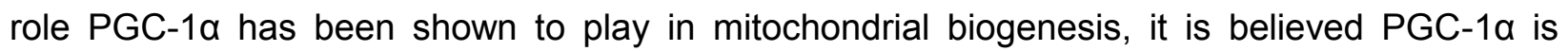
involved in regulating several genes involved in ROS defense. PGC-1 $\alpha$ activity has been strongly associated with superoxide dismutase (SOD) and glutathione peroxidase expression. ${ }^{49}$ In many contexts, PGC-1a can promote uncoupling protein expression which can dissipate the mitochondrial proton gradient, resulting in lesser potential for ROS formation. ${ }^{38}$ Consistent with this role, PGC-1a KO mice display elevated levels of ROS in a multitude of highly metabolically active tissues such as brain and muscle. ${ }^{50}$ This additional role as a promoter of antioxidant defense makes PGC-1 $\alpha$ an intriguing therapeutic target in conditions where the oxidative stress aspect of mitochondrial dysfunction plays a prominent role.

\section{4}

\section{IL-15: A potential novel target in mitochondrial dysfunction:}

IL-15 is a recently discovered four-helix bundle cytokine which has been heavily studied regarding its role in regulating immune homeostasis. IL-15 has been characterized as a lymphocyte differentiation factor as well as promoter of natural killer cell maturation. ${ }^{51} \mathrm{IL}-15$ is also believed to be a potent inflammatory chemokine and has been shown to be essential in directing immune responses in inflammatory conditions such as arthritis ${ }^{52,53}$ and celiac disease. $^{54}$ Over-activity of IL-15 can induce chronic inflammatory states and autoimmune 
conditions through the promotion of t-cell auto-reactivity and as a result, its activity is tightly regulated through a wide variety of pre and post-translational mechanisms. ${ }^{51}$ One of the primary regulators of IL-15 activity is a non-signaling receptor known as IL-15Ra. IL-15Ra is not a traditional receptor in that it does not have the capacity for signal transduction, and is more aptly though of simply as an IL-15 binding protein. ${ }^{55,56}$ Despite the fact that IL-15 and IL-15Ra are expressed in virtually every tissue ${ }^{56,57} \mathrm{IL}-15$ function in non-immune tissues is widely unknown.

Data collected by our laboratory using a transgenic mouse model lacking IL-15R $\alpha$ suggests that IL-15 is a potential regulator of mitochondrial biogenesis in skeletal muscle. Electron micrographs have provided evidence that muscle tissue from the transgenic line contains up to $40 \%$ more mitochondrial mass than muscle extracted from wild type mice when analyzed by point counting. ${ }^{15}$ Supporting quantitative PCR analysis shows an increase in mitochondrial DNA content ${ }^{15}$ and western blot has shown increased protein levels of cytochrome oxidase.$^{16}$ Mitochondria-rich muscle from the knock out model is functional and displays increased oxidative capacity when analyzed using ex-vivo functional tests; fatigue profiling has revealed that extensor digitorum longus muscle from the $\mathrm{KO}$ line is significantly more fatigue resistant compared to controls. ${ }^{16}$ Furthermore, significant increases in PPAR $\delta$ and PGC-1 $\alpha$ mRNA in transgenic muscle suggests that the higher mitochondrial density and increased oxidative capacity observed in the $\mathrm{KO}$ line is a result of mitochondrial biogenesis stimulated by increased PGC1 1 activity. ${ }^{16}$ The changes seen in muscle as a result of IL-15Ra loss make IL-15 and IL-15R $\alpha$ potential targets for therapies in conditions of mitochondrial dysfunction. However, the mechanisms by which loss of IL-15Ra results in mitochondrial changes have not yet been elucidated, as IL-15 signaling mechanisms in skeletal muscle have been virtually un-explored.

Skeletal muscle constitutes the largest IL-15 mRNA pool in the body, and loss of IL$15 R a$ in the global KO mouse has been shown to result in increases in muscle IL-15 transcript. ${ }^{16}$ This observation, combined with observations of dramatic increases in circulating IL- $15,{ }^{58}$ led to the suggestion that IL-15 secretion from skeletal muscle is increased as a direct result of IL15Ra loss. ${ }^{16,17}$ Furthermore, based on studies reporting similar oxidative muscle changes and exercise phenotypes in animals with systemically elevated IL-15, ${ }^{59,60}$ it was suggested that this increase in circulating IL-15 acts directly on skeletal muscle, resulting in the pro-oxidative changes originally observed in the global IL-15Ra KO mouse (Figure 1)..$^{17}$ However, this mechanistic explanation for the muscle phenotype observed in the global IL-15Ra KO mouse would suggest that IL-15 signaling in skeletal muscle differs in some aspects from what is 
Figure 1. Currently proposed mechanism of pro-oxidative muscle remodeling with loss of IL-15Ra.

(1) Loss of IL-15Ra as an inhibitory transcriptional cofactor in skeletal muscle results in an increase in IL15 transcription and secretion. (2) Increases in secreted IL-15 act directly on skeletal muscle in an autocrine fashion to increase IL-15 signal transduction. (3) Increases in IL-15 signaling directly induce pro-oxidative gene expression and promote oxidative remodeling.

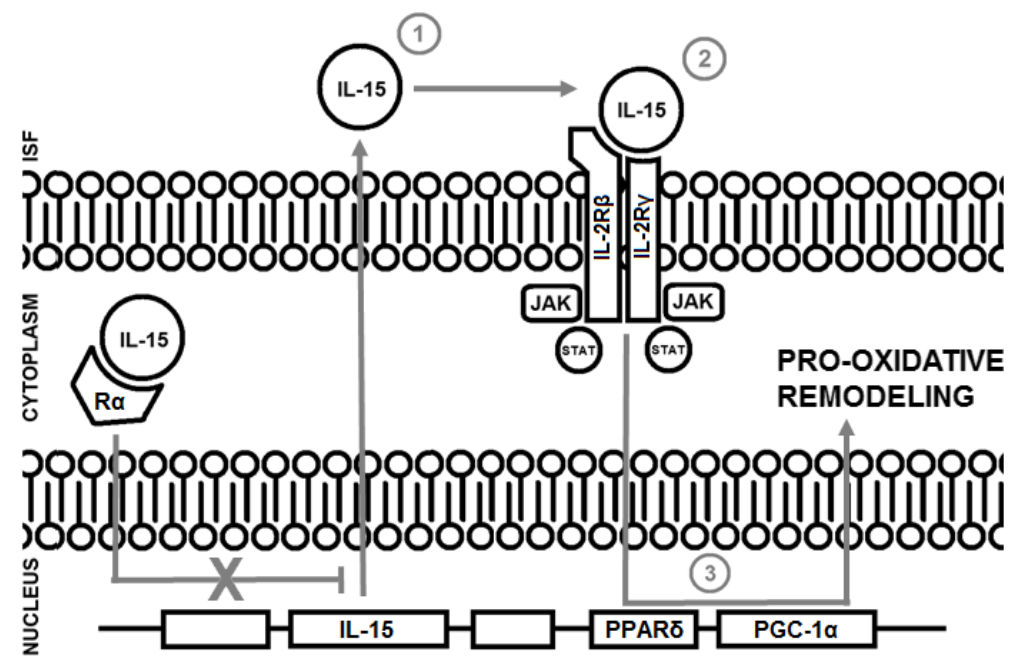

observed in the immune system, where IL-15Ra is essential for the ability of cells to secrete and respond to IL-15. ${ }^{18-22,61}$

In immune cells, IL-15 activity is regulated in terms of transcription, secretion, and signal transduction by several soluble and membrane bound isoforms of IL-15R $\alpha$ which are generated through alternative splicing. ${ }^{62}$

An intracellular isoform of IL-15Ra has been shown to play a potentially pivotal role in regulating IL-15 at the transcriptional level. Intracellular IL-15Ra contains a nuclear translocation domain and is commonly observed associated with the nuclear membrane in histochemical and cytochemical analysis and has been detected in nuclear protein fractions. ${ }^{63}$ Evidence has been shown that during states of high IL-15 production such as inflammation, intracellular IL-15-Ra binds cytosolic IL-15, translocates to the nucleus, and limits further IL-15 transcription potentially through function as an inhibitory transcriptional cofactor (Figure $2 \mathrm{~A}$ ). ${ }^{63}$ It is logical to believe that loss of IL-15Ra in this context may account for the mechanism by which an increase in muscle IL-15 mRNA is observed in the global knockout mouse. However, studies exploring the role that IL-15Ra plays in regulating IL-15 secretion in the immune system would suggest that this increase in IL-15 mRNA may not result in an increase in IL-15 release in the absence of IL15Ra. ${ }^{18,20,64}$

IL-15 contains an inefficient signal peptide and free IL-15 is not easily secreted from the cell. ${ }^{64}$ While secretion of free IL-15 does occur, it is released much more effectively using IL$15 R \alpha$ as a chaperone. Certain splice variants of IL-15R $\alpha$ contain a highly effective signal peptide which allows for easy secretion; association of a soluble isoform of IL-15Ra with IL-15 
within the secretory pathway allows for the secretion of a soluble IL-15Ra /IL-15 complex which is more efficiently released than IL-15 alone (Figure $2 \mathrm{~B}$ ). ${ }^{20} \mathrm{IL}-15$ can also internally dimerize with a transmembrane domain-containing isoform of IL-15R a and be presented at the plasma membrane where it can signal as a cell surface marker. ${ }^{18}$ This role of IL-15Ra as a chaperone to secretion in the immune system presents an obvious contradiction to the increases in circulating IL-15 reported in the IL-15R $\alpha$ KO mouse.

IL-15Ra not only regulates IL-15 activity at the transcriptional and secretory level, in the immune system, IL-15Ra is also heavily involved in modulating IL-15 signal transduction. On immune cells, IL-15 signals via a receptor complex composed of interleukin 2 receptor beta (IL$2 \mathrm{R} \beta$ ) and the common cytokine receptor gamma chain $(\mathrm{yc})$ by way of classic receptor tyrosine kinase mechanisms. ${ }^{57}$ Both IL-2R $\beta$ and yc contain cytoplasmic domains capable of janus kinase 3 (JAK3) association. IL-15 binding results in ligand induced dimerization of IL-2R $\beta$ and $y c$ allowing for JAK3 trans-phosphorylation, an event which promotes the phosphorylation of several $n$-terminus tyrosine residues on both receptors. N-terminus tyrosine phosphorylation allows for the recruitment and phosphorylation of cytoplasmic signal transducer and activator of transcription (STAT) family members, most notably STAT5. These phosphorylated STATs dissociate from the receptor complex, form various homo and heterodimers, and ultimately initiate transcriptional changes. ${ }^{65}$ Presence of IL15-Ra in a variety of signaling scenarios greatly enhances the ability of IL-15 to signal through IL-2R $\beta$ and yc. Association of IL-15Ra with IL-15 results in a slight conformational change which enhances the ability of $\mathrm{IL}-15$ to bind to the signaling receptors; the soluble secreted IL-15Ra/IL-15 complex exhibits 150-fold greater affinity for the IL-15 signaling receptors than free IL-15 alone (Figure 2C). ${ }^{66,67}$ A membrane-bound isoform of IL-15Ra is often closely associated with the IL-15 signaling receptors at the plasma membrane, forming a trimeric receptor complex. While IL-15Ra does not contain a cytoplasmic domain and does not potentiate an intracellular signal, its presence in the trimeric complex greatly increases the affinity of free IL-15 for the signaling receptors in a stepwise fashion. In the trimeric receptor complex scenario, free IL-15 first binds membrane- bound IL-15Ra, binding results in an IL-15 conformational change, and IL-15 then strongly associates with the signaling receptors and signaling is initiated (Figure $2 \mathrm{C}$ ). ${ }^{66}$ One of the most important and well characterized immune signaling mechanisms in IL-15 biology is the process of transpresentation, a process in which IL-15Ra is essential. During trans-presentation, membranebound IL-15R $\alpha$ presents IL-15 as a cell surface marker. This membrane tethered IL-15 can then interact with and initiate signaling through the IL-15 signaling receptors located on adjacent and 
A

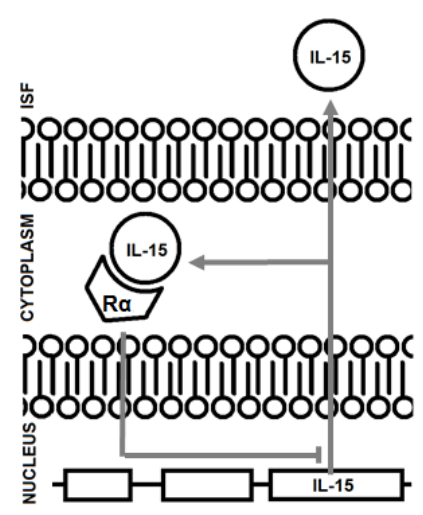

B

$\begin{array}{ll}\text { HIGH } & \text { LOW } \\ \text { EFFICIENCY: } & \text { EFFICIENCY: }\end{array}$

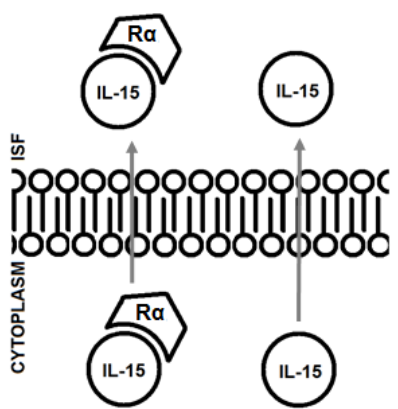

C

LOW HIGH HIGH AFFINITY: $\quad$ AFFINITY: $\quad$ AFFINITY:
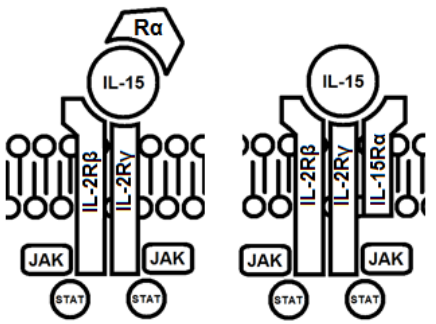

Figure 2. Regulatory actions of IL-15Ra within the immune system.

(A) During states of high IL-15 production such as inflammation, Intracellular IL-15Ra can bind intracellular IL-15 in the cytoplasm and translocate to the nucleus where it can act to inhibit further IL-15 transcription. (B) Intracellular IL-15Ra can bind IL-15 in the secretory pathway, forming a heterodimer which is more efficiently secreted than the IL-15 free monomer. (C) The presence of IL$15 \mathrm{Ra}$ in the IL-15/IL-15Ra heterodimer or as a membrane bound receptor greatly increases the affinity of IL-15 for the signal transducing complex of IL-2R $\beta$ and IL-2Ry.

surrounding cells. Trans-presentation is the primary signaling mechanism by which IL-15 induces lymphocyte differentiation and NK-cell development. ${ }^{18,21,68}$ This action can be ablated by the action of a metalloprotease known as tumor necrosis factor a converting enzyme (TACE). TACE cleaves IL-15R $\alpha$, releasing the IL-15/IL-15R $\alpha$ complex from the plasma membrane, eliminating the potential for trans presentation. ${ }^{69}$ Due to the fact that IL-15Ra does not potentiate an intracellular signal in any of these scenarios, it is believed that IL-15 signal transduction can still occur in its absence. ${ }^{70}$ However, if IL-15R $\alpha$ plays a similar regulatory role in skeletal muscle as it does in the immune system, it is logical that an increase in IL-15 signal transduction is unlikely in the muscle of the global IL-15Ra KO mouse as previously suggested, even in the presence of increased circulating IL-15.

In addition to the paradoxes the previously proposed mechanism for the oxidative changes observed in the IL-15Ra global KO mouse present to immune IL-15 signaling, it is further complicated by the fact that IL-15Ra is ubiquitously absent in the model, making it difficult to determine whether the effects of IL-15Ra loss in non-muscle tissues contribute to the changes characterized in skeletal muscle, or whether these changes were a direct result of IL$15 \mathrm{Ra}$ loss in muscle tissue. In the CNS, IL-15 and IL-15Ra have been shown to play an essential role in regulating the turnover and synaptic reuptake of gamma-aminobutyric acid (GABA), the most prevalent inhibitory neurotransmitter in the central nervous system. ${ }^{71} \mathrm{IL}-15 \mathrm{R} \alpha$ KO mice display significantly depressed GABA levels, a phenotype commonly seen in attention 
deficit and hyperactivity disorders. ${ }^{71}$ IL-15R $\alpha$ KO mice display a hyperactive phenotype ${ }^{16,71,72}$ and it is possible that the increases in mitochondrial mass and changes in PGC-1 $\alpha$ observed in this model are simply a result of adaptations which are commonly seen with increases in physical activity. IL-15 has also been shown to stimulate the release of free-fatty acids from adipocytes and promote fat metabolism. ${ }^{73-75} \mathrm{IL}-15 \mathrm{Ra} \mathrm{KO}$ mice are leaner ${ }^{16}$ and display respiratory exchange ratio (RER) values indicative of increased fat metabolism. ${ }^{58}$ Increased exposure of the muscle to fatty acid substrates by way of IL-15-mediated adipocyte fatty acid release could increase the activity of PPARs and PGC-1 $\alpha$, as they are sensitive to cellular fatty acid load. Due to the general complexity of cytokine signaling, it is possible that alterations in IL15-mediated release of any number of factors from numerous cell types could be the cause of the oxidative phenotype observed in the IL-15Ra KO mouse.

Thus, based on the lack of current knowledge regarding the exact function and mechanism of IL-15 signaling in skeletal muscle, as well as the promising mitochondrial changes observed with loss of IL-15Ra in the global KO mouse, the mechanism responsible for the pro-oxidative muscle changes which have been observed with IL-15Ra loss warrant further investigation.

\section{5}

\section{Background summary, aims, and hypotheses:}

Therapies which increase mitochondrial mass by way of PGC-1 $\alpha$ activation have shown great promise in offsetting the detrimental effects of mitochondrial dysfunction, a condition implicated in the pathologies of some the most prevalent and severe human diseases and disorders. Altering IL-15 signaling through ablation of IL-15Ra in the IL-15Ra global KO mouse has been shown to potently stimulate mitochondrial biogenesis in skeletal muscle via PGC-1a, implicating IL-15 and IL-15R as potential targets in conditions of mitochondrial dysfunction if the mechanisms involved can be elucidated. However, IL-15 signaling in skeletal muscle remains virtually unexplored. It has been previously suggested that loss of IL-15Ra in the global $\mathrm{KO}$ mouse directly results in an increase in muscle IL-15 secretion, and this increase in secreted IL-15 acts on skeletal muscle in an autocrine fashion, directly stimulating pro-oxidative remodeling. However, this mechanistic explanation for the pro-oxidative changes observed in the skeletal muscle of the IL-15Ra KO mouse is complicated by the fact that IL-15Ra is absent in all tissues, making it difficult to determine whether the changes observed in muscle are a direct result of IL-15Ra loss in the muscle alone, or if changes in non-muscle tissues play a 
contributing role. In an additional complication, this mechanistic explanation would suggest that IL-15 signaling in skeletal muscle differs in some aspects from what is observed in the immune system, in which IL-15Ra is essential for the ability of cells to secrete and respond to IL-15.

Therefore, this project had three specific aims: first, to determine how loss of IL-15Ra in skeletal muscle influences IL-15 secretion, second, to determine how loss of IL-15Ra impacts the ability of skeletal muscle to respond to IL-15, and third, to determine whether IL-15 acts directly on skeletal muscle to induce pro-oxidative changes. The first two of these aims were addressed in vitro via the generation of $\mathrm{C}_{2} \mathrm{C}_{12}$ myoblasts lacking IL-15Ra, as well as in-vivo using a conditional muscle specific IL-15Ra mouse model. It was hypothesized that loss of IL$15 \mathrm{R} \alpha$ would result in an increase in IL-15 secretion. Furthermore, it was hypothesized that loss of IL-15Ra would negatively impact the ability of skeletal muscle to respond to IL-15, but that IL15 signaling could persist without IL-15Ra in the presence of sufficiently elevated levels of IL15. The third aim was addressed through the treatment of skeletal muscle cultures with recombinant IL-15. It was hypothesized that IL-15 treatment would result in a similar increase in mitochondrial mass as observed in the IL-15Ra global KO mouse. 


\section{Chapter 3.}

\section{Results:}

\section{1}

\section{Generation of stable IL-15Ra KO myoblasts:}

In order to address the effects of IL-15R $\alpha \mathrm{KO}$ in skeletal muscle on IL-15 secretion and IL-15 signal transduction, transgenic myoblast cell lines lacking IL-15Ra were generated via stable transfection of $\mathrm{C}_{2} \mathrm{C}_{12}$ mouse myoblasts with plasmid vectors encoding a tGFP reporter and one of two independent short hairpin RNAs (shRNA) against IL-15Ra. Wild type $\mathrm{C}_{2} \mathrm{C}_{12}$ cells along with a stable cell line carrying the empty plasmid vector were used as controls for all experiments. PCR targeting tGFP in isolated genomic DNA demonstrated stable plasmid integration into the genome of all three transfected cell lines (Figure 3B). RT-PCR targeting tGFP mRNA as well as visual detection of GFP fluorescence indicated plasmid expression following genomic integration (Figure 3A, 3B). RT-PCR targeting IL-15Ra demonstrated a selective knockout of IL-15Ra in both shRNA carrying cell lines, while IL-15Ra mRNA was

A
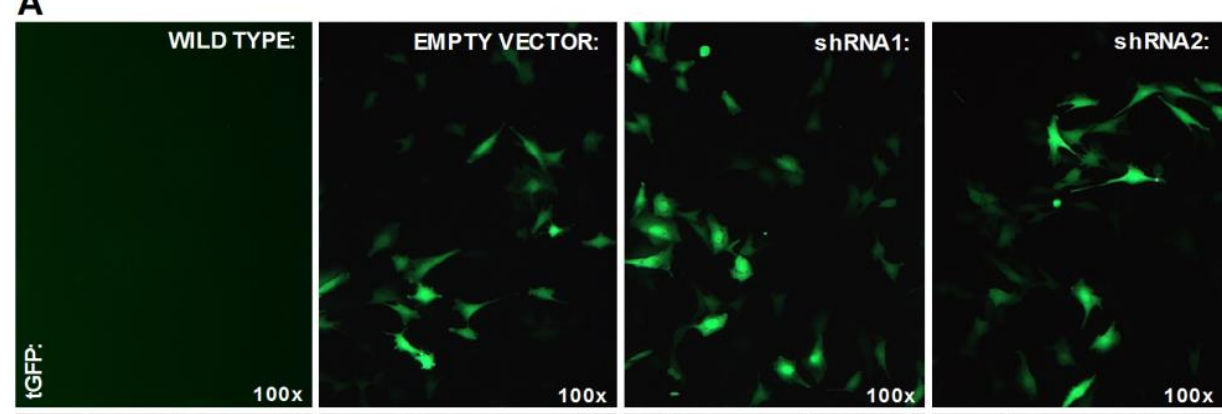

B
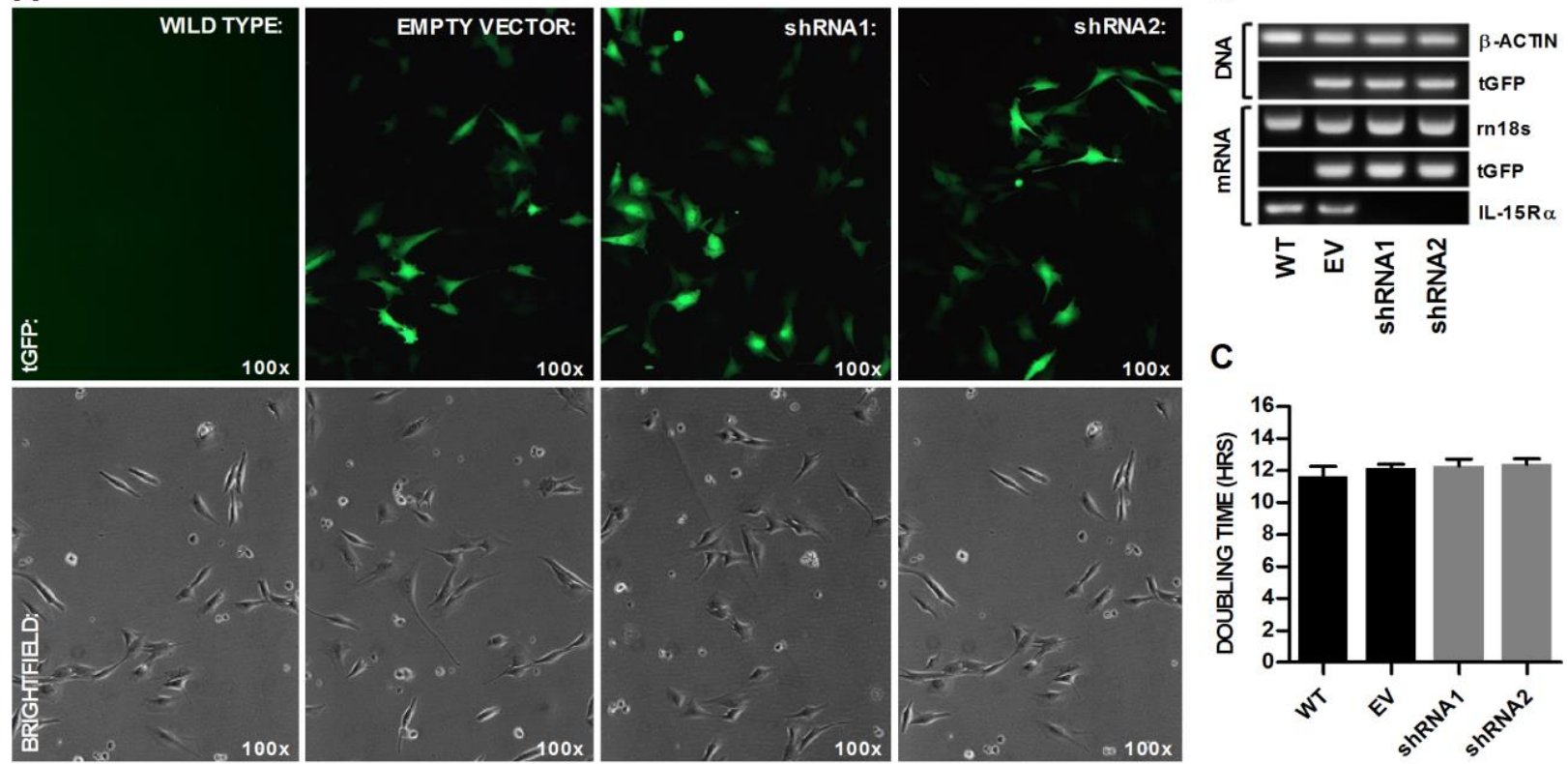

C

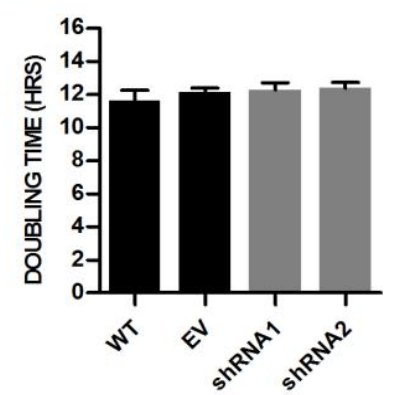

Figure 3. Characterization of stable cell lines.

(A) Visualization of tGFP reporter expression in IL-15Ra null and control myoblasts. (B) tGFP PCR with DNA and cDNA templates from mature myotubes indicating stable plasmid integration and expression in transgenic cell lines. IL-15Ra-targeted RT-PCR indicating effective IL-15Ra knockdown in mature myotubes stably carrying shRNAs. (C) No differences in doubling time were observed between IL-15R $\alpha$ null and control myoblasts. Data represent mean \pm SE for 4 independent experiments. 
clearly detected in the empty vector and wild type controls (Figure 3B). Stable transfection did not alter the proliferation rate of the transgenic myoblasts, as compared to wild type $\mathrm{C}_{2} \mathrm{C}_{12}$ myoblasts of a similar passage number (Figure $3 \mathrm{C}$ ).

\section{2}

\section{Effects of chronic IL-15 treatment in the presence and absence of IL-15Ra:}

In order to examine the effects of IL-15 treatment on mitochondrial density in vitro, as well as to determine the effects of IL-15Ra loss on IL-15 response, WT and stable cells were stimulated with IL-15 chronically during myotube formation and mitochondrial mass was assessed via MitoTracker staining and mtDNA content was quantified using qPCR. Quantification of mitotracker staining revealed a significant increase in MitoTracker staining per nuclei in WT and EV cultures treated with $25 \mathrm{ng} \cdot \mathrm{mL}^{-1} \mathrm{IL}-15$, suggesting an increase in mitochondrial mass. This effect was not observed in WT and EV treated with higher doses of IL15. No significant differences in MitoTracker staining were observed with IL-15 treatment in either cell line lacking IL-15Ra, suggesting that this response requires IL-15Ra. Additionally, cultures lacking IL-15Ra exhibited significantly less MitoTracker staining than WT and EV controls under all treatment conditions (Figure 4A). No differences were observed in mtDNA
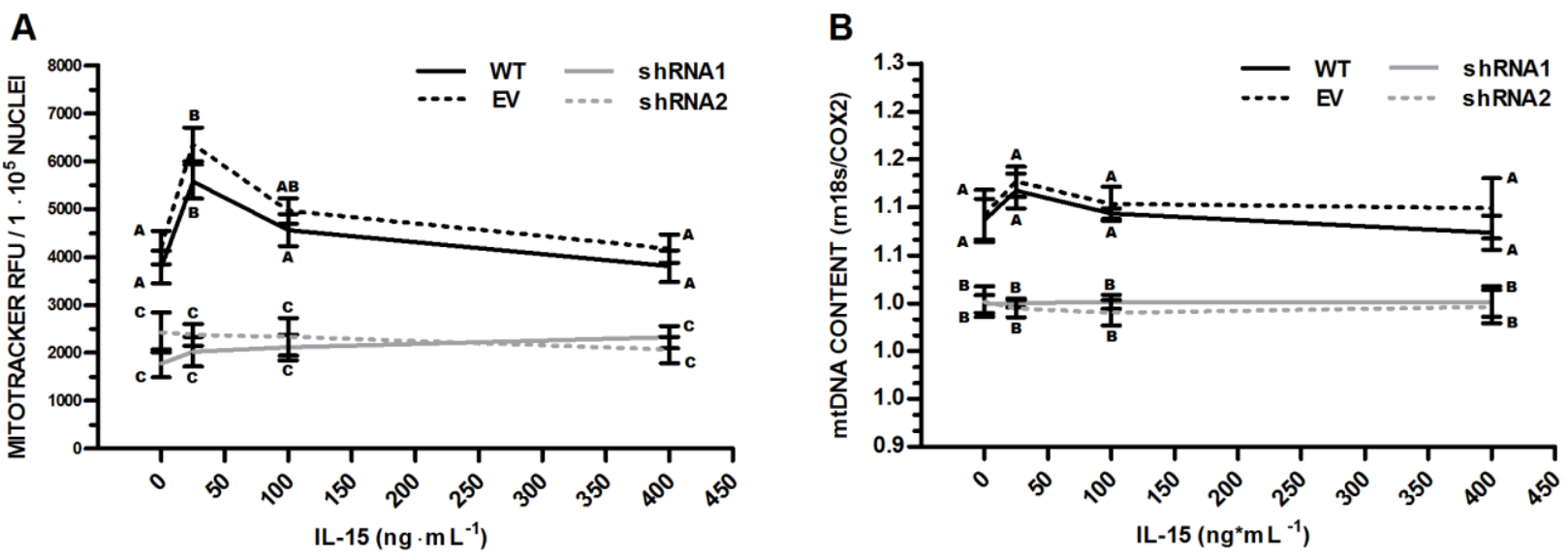

Figure 4. Effects of chronic IL-15 treatment on mitochondrial density.

(A) EV and WT cultures chronically treated with $25 \mathrm{ng} \cdot \mathrm{mL}^{-1} \mathrm{IL}-15$ exhibited a significant increase in mitochondrial mass in comparison to EV and WT cultures which were untreated or treated with higher doses of IL-15. IL-15 treatment had no significant effect on mitochondrial mass in cell lines lacking IL-15Ra. Cultures lacking IL-15Ra exhibited significantly less mitochondrial mass in comparison to WT and EV cultures under all conditions. (B) No differences in mtDNA content were observed were observed in any cell line with IL-15 treatment. Cell lines lacking IL-15Ra displayed significantly lower mtDNA content in comparison to WT and EV controls. Data represent mean \pm SE for 4 independent experiments. Letters denote statistically identical means. 
content with IL-15 treatment in any cell line, however, shRNA carrying cell lines exhibited significantly lower mtDNA counts in comparison to controls (Figure 4B)

In order to determine whether the alterations in mitochondrial mass observed with both IL-15 treatment and IL-15Ra loss were a result of altered myogenesis or myotube morphology, cultures were visually assessed with microscopy and both fusion index and myotube diameter was analyzed. Visually, the $25 \mathrm{ng} \cdot \mathrm{mL}^{-1} \mathrm{IL}-15$ treatment appeared to result in a hypertrophic myotube phenotype in EV and WT cultures, with myotubes in these cultures appearing to be of greater mass than those in EV and WT cultures which were either untreated or treated with higher doses of IL-15. Strikingly, cultures lacking IL-15Ra appeared under-fused with thin
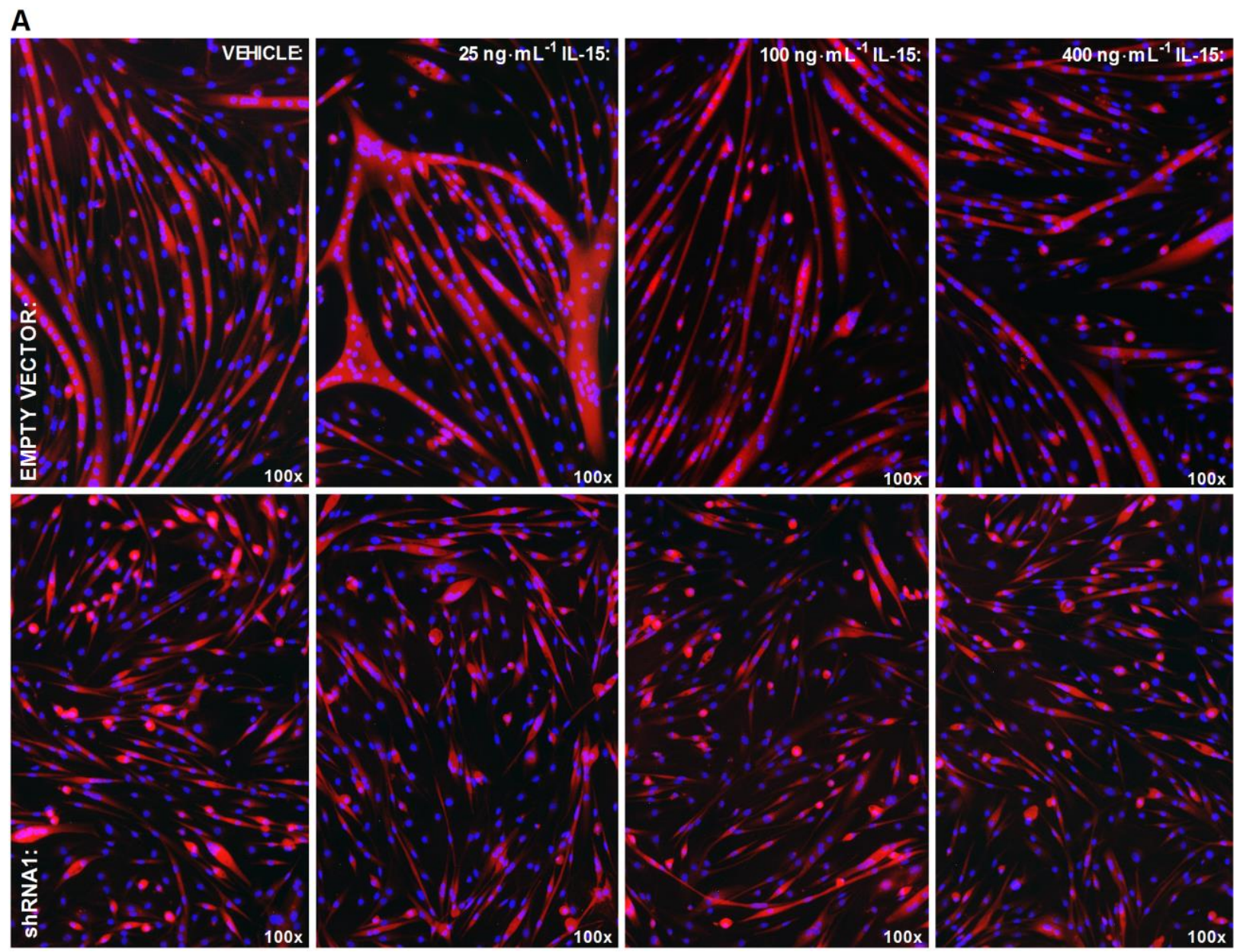

Figure 5. Effects of chronic IL-15 treatment on mytube morphology.

(A) EV and WT cultures chronically treated with $25 \mathrm{ng} \cdot \mathrm{mL}^{-1}$ recombinant IL-15 visually appeared to contain myotubes of greater mass than EV and WT cultures which were untreated or treated with higher doses of IL-15. IL-15 treatment did not result in visually observable morphologic changes in cultures lacking IL-15Ra. Visually, cultures lacking IL-15Ra appeared less fused with smaller myotubes as compared to controls. 
myotube formations containing limited nuclei (Figure 5A).

Confirming these visual observations, measurement of myotube diameter revealed a rightward shift in diameter distribution along with a significant increase in mean myotube diameter in WT and EV cultures treated with IL-15 at the $25 \mathrm{ng} \cdot \mathrm{mL}^{-1}$ dose, suggesting that IL-15 treatment can result in an increase in myotube size. IL-15 treatment failed to yield a response in terms of mytotube diameter at any dose in cultures lacking IL-15R $\alpha$, suggesting that IL-15R $\alpha$ is required for this response. Cultures lacking IL-15Ra displayed depressed mean myotube diameters and leftward-shifted diameter distributions compared to control cultures under all experimental conditions, suggesting that loss of IL-15R $\alpha$ can negatively impact myotube size (Figure 6A, 6B).

In terms of fusion index, which is expressed as the ratio of fused to total nuclei, IL-15 treatment failed to induce any significant change in fusion index at any dose in all four cell lines. However, cultures lacking IL-15Ra were significantly less fused than controls under all experimental conditions, suggesting that loss of IL-15Ra impairs myotube formation (Figure 6C). No significant differences were observed in the total number of nuclei per field observed between any set of experimental conditions, suggesting that the changes observed in both myotube diameter and fusion index were not a result of altered culture nuclear content (Figure 6D).

Semi-quantitative RT-PCR targeting myosin heavy chain (MYH) was performed as a molecular assessment of myogenic state. In EV and WT cultures, an increase in MYH mRNA was detected with IL-15 treatment at the $25 \mathrm{ng} \cdot \mathrm{mL}^{-1}$ dose as compared to EV and WT cultures which were either untreated or treated with higher doses of IL-15. IL-15 treatment failed to yield a response in terms of MYH expression at any dose in cultures lacking IL-15Ra, once again inferring a need for IL-15Ra in the ability to respond to IL-15. Consistent with our image analysis, cultures lacking IL-15R a displayed less detectable MYH mRNA as opposed to WT and EV controls under all treatment conditions (Figure 7A).

In-situ ponceau staining was performed to quantify total cellular protein accretion; ponceau staining was normalized to nuclear count, yielding a protein to nuclei ratio. In support of the changes of MYH expression that were observed, significant increases in total culture protein were observed in EV and WT lines treated with the $25 \mathrm{ng} \cdot \mathrm{mL}^{-1}$ dose of IL-15, with IL-15 treatment failing to yield a similar increase in IL-15Ra null cultures. Furthermore, cultures 
A
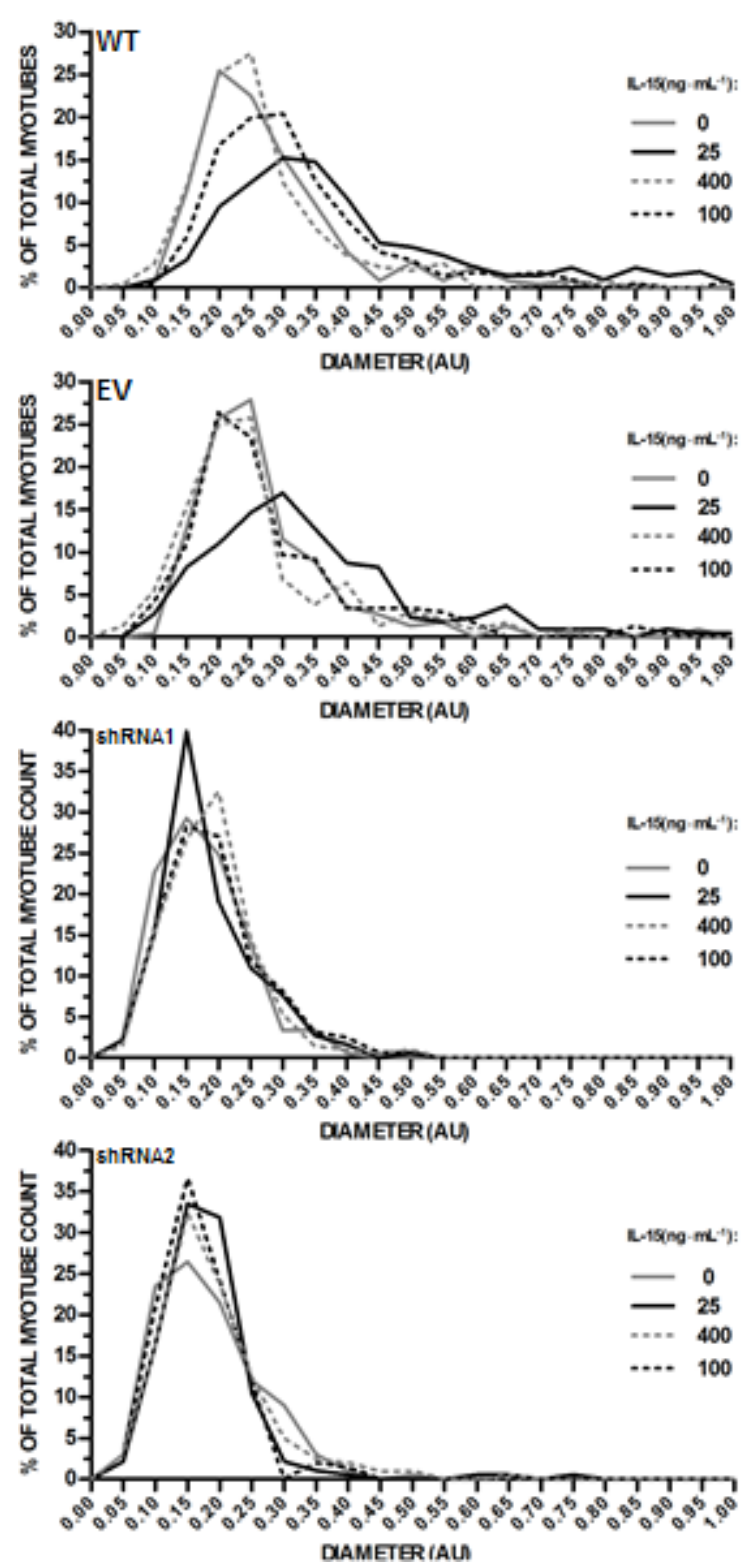

B

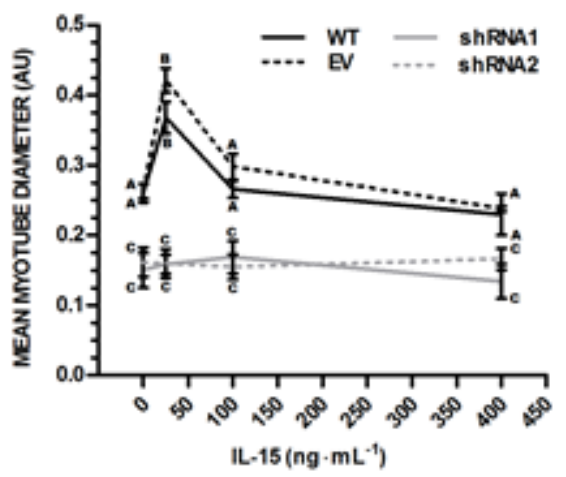

C

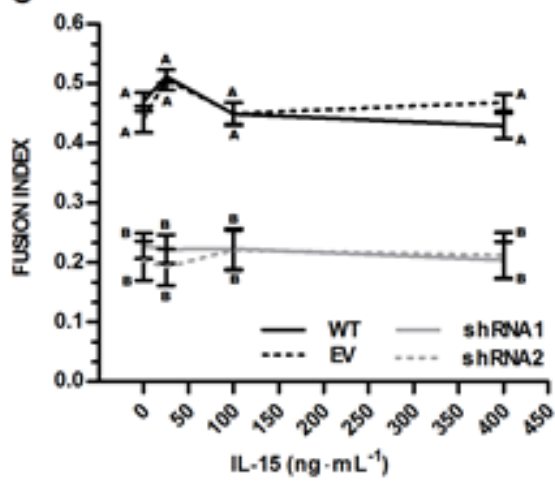

D

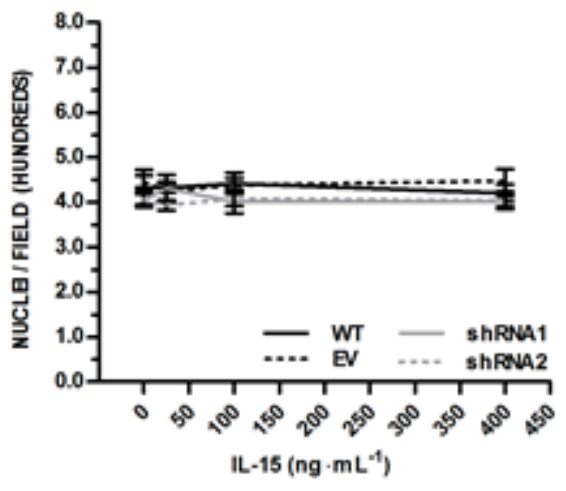

Figure 6. Quantification of myotube morphology following chronic IL-15 treatment.

(A) Chronic treatment of wild type and empty vector cultures with $25 \mathrm{ng} \cdot \mathrm{mL}^{-1} \mathrm{IL}-15$ during myogenesis resulted in a rightward shift in myotube diameter distribution. Treatment of IL-15Ranull cultures failed to yield a similar response at any dose. Diameter distributions generated from cultures lacking IL-15Ra are shifted leftward in comparison to controls. (B) Chronic treatment with $25 \mathrm{ng} \cdot \mathrm{mL}^{-1} \mathrm{IL}-15$ resulted in a significant increase in myotube diameter in EV and WT cultures. IL-15 treatment had no significant effect on myotube diameter in cell lines lacking IL-15Ra. Cultures lacking IL-15Ra exhibited significantly reduced myotube diameter in comparison to WT and EV cultures under all conditions. (C) IL-15 did not affect the fusion index of any treated cell line. Cultures lacking IL-15Ra exhibited significantly depressed fusion index in comparison to WT and EV cultures under all conditions. (D) No differences in total nuclei per field were observed between any experimental conditions. Data represent mean $\pm S E$ for 3 independent experiments. Letters denote statistically identical means. 
A
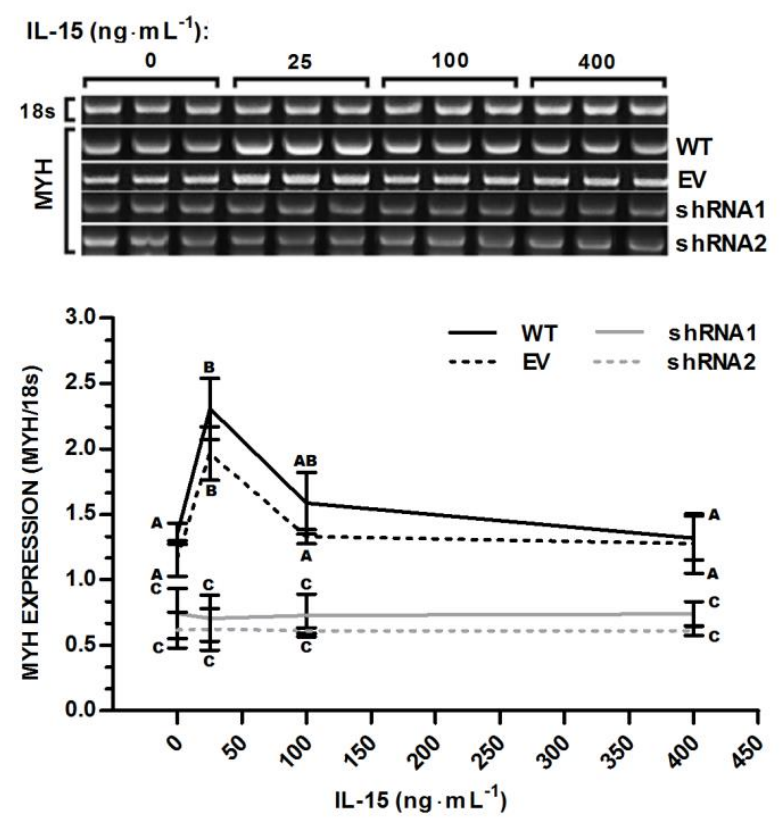

B

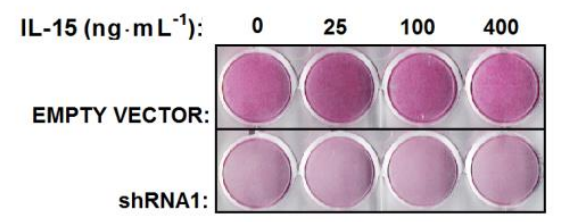

C

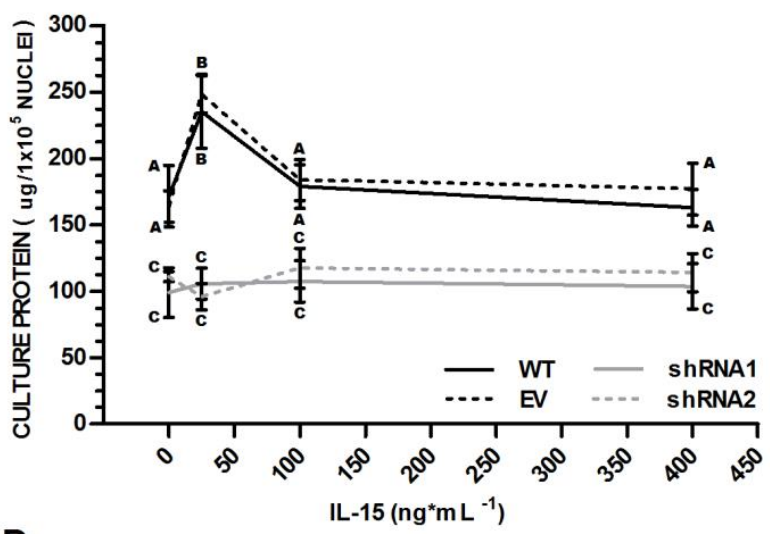

D

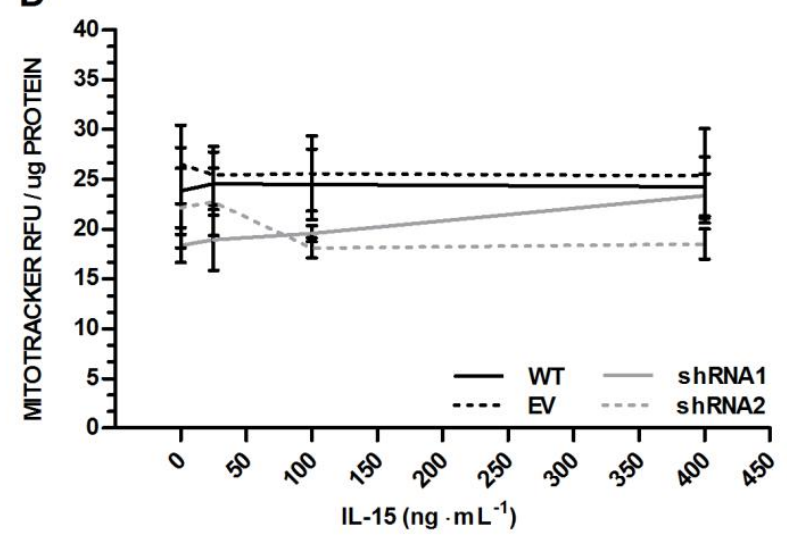

Figure 7. Molecular characterization of myogensis following chronic IL-15 treatment.

(A) Chronic treatment with $25 \mathrm{ng} \cdot \mathrm{mL}^{-1} \mathrm{IL}-15$ resulted in a significant increase in MYH mRNA expression EV and WT cultures. IL-15 treatment had no significant effect on MYH expression in cell lines lacking IL-15Ra. Cultures lacking IL-15Ra exhibited significantly less MYH expression in comparison to WT and EV cultures under all conditions. (B) Chronic treatment of WT and EV cultures with $25 \mathrm{ng} \cdot \mathrm{mL}^{-1} \mathrm{IL}-15$ resulted in a visually apparent increase in ponceau staining. No similar effect was observed in IL-15Ra deficient cultures at any dose. Cultures lacking IL-15R displayed less prominent ponceau staining when compared to controls. (C) Chronic treatment with $25 \mathrm{ng} \cdot \mathrm{mL}^{-1} \mathrm{IL}-15$ resulted in a significant increase in the protein to nuclei ratio of EV and WT cultures. IL-15 treatment had no significant effect on protein accretion in cell lines lacking IL-15Ra. Cultures lacking IL-15R $\alpha$ exhibited significantly lower protein to nuclei ratios in comparison to WT and EV cultures under all conditions. (D) There are no significant differences in mitochondria to protein ratio among any experimental conditions. Data represent mean $\pm S E$ for 4 independent experiments. Letters denote statistically identical means.

lacking IL-15Ra displayed lower protein content as opposed to WT and EV controls across all treatment conditions (Figure 7B, 7C).

Taken as a whole, our analysis of myotube morphology and myogenic state suggests that the changes observed in mitochondrial mass with IL-15 treatment and IL-15Ra loss were confounded by altered myotube size and myogenic fusion. This is apparent when mitochondrial 
mass is normalized to total cellular protein, as no significant differences in mitochondria to protein ratio are observed between any experimental conditions (Figure 7D).

\section{3}

\section{Effects of acute IL-15 treatment on pro-oxidative gene expression:}

Because of the confounding effects of chronic IL-15 treatment on myotube morphology when examining the effects of IL-15 treatment on mitochondrial density, we alternatively examined the effects of acute IL-15 treatment on pro-oxidative gene expression in mature WT myotubes. Fully differentiated myotubes were stimulated with $25 \mathrm{ng} \cdot \mathrm{mL}^{-1} \mathrm{IL}-15$ for either $0,1,3$,

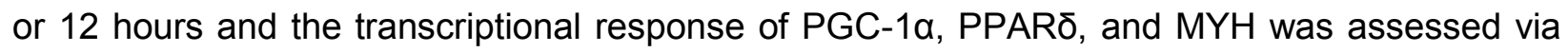
semi-quantitative RT-PCR. A significant increase in PPAR $\delta$ expression relative to vehicle was observed after one hour of stimulation with IL-15, with this effect dissipating between 3 and 12 hours of stimulation (Figure 8A). Concurrently, a significant increase in PGC-1a expression relative to vehicle was observed from 3 to 12 hours of IL-15 stimulation (Figure 8B). No significant increases in $\mathrm{MYH}$ were observed at any time point (Figure $8 \mathrm{C}$ ). These results

A

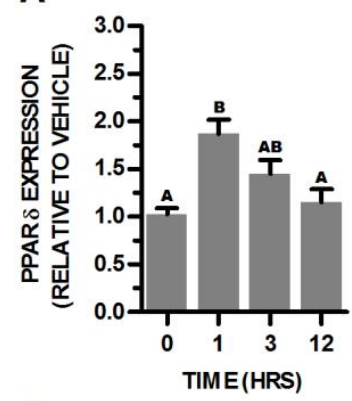

C

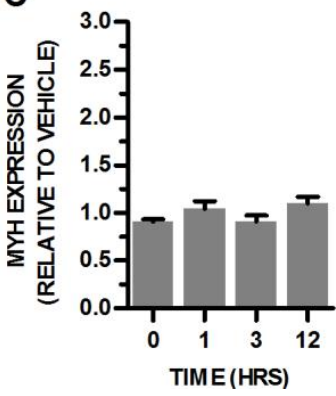

B

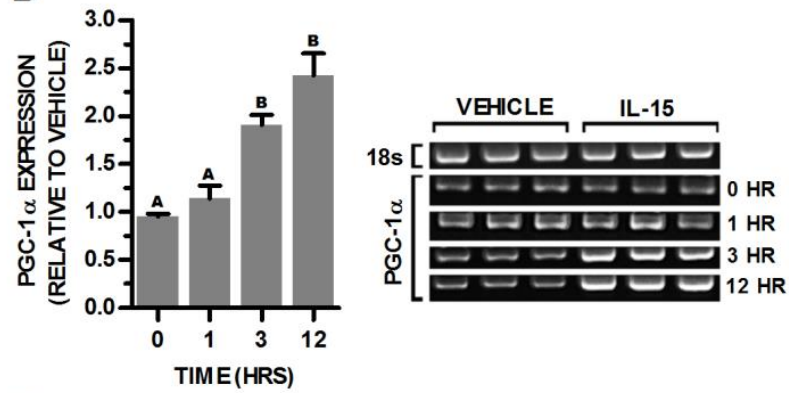

D

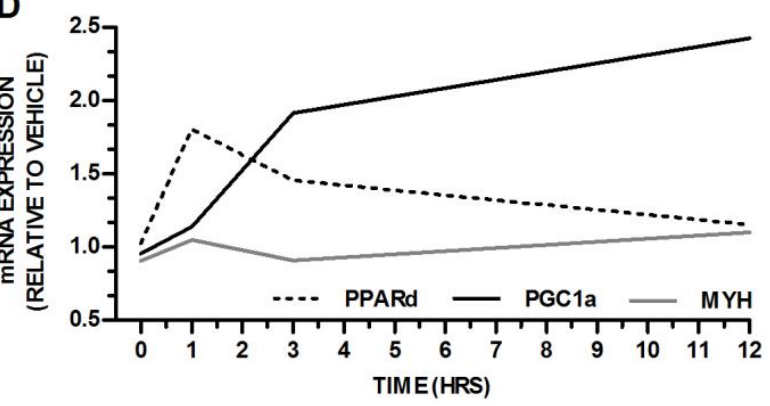

Figure 8. Effects of acute IL-15 treatment on pro-oxidative gene expression.

(A) Mature WT mytubes treated with recombinant IL-15 exhibited a significant increase in PPAR $\delta$ mRNA expression following one hour of treatment. (B) A significant increase in PGC-1a mRNA expression was observed in cultures treated with IL-15 from 3 to 12 hours. (C) No significant changes in MYH expression were observed with up to 12 hours of IL-15 treatment. (D) Time course of gene expression changes observed with acute IL-15 treatment. Data represent mean \pm SE for 4 independent experiments. Letters denote statistically identical means. 
suggest that acute IL-15 treatment can induce pro-oxidative gene expression in a manner that proceeds or avoids the changes in MYH expression observed with chronic IL-15 treatment (Figure 8D).

\section{4}

\section{Effects of IL-15Ra loss on IL-15 secretion In-Vitro:}

In order to determine the effects of IL-15Ra loss on IL-15 secretion in-vitro, fully differentiated myotubes lacking IL-15Ra were stimulated with lipopolysaccharide (LPS) in an attempt to drive IL-15 secretion, and secreted IL-15 was measured in the cell culture supernatant via ELISA and normalized to culture total cellular protein. EV and WT myotubes exhibited a robust IL-15 secretory response to LPS stimulation at both 1 and $5 \mathrm{ug} \cdot \mathrm{mL}^{-1}$. However, cultures lacking IL-15R a failed to exhibit an increase in IL-15 secretion in response to LPS and also displayed significantly lower levels of IL-15 in cell culture supernatants under basal conditions as opposed to controls (Figure 9A). No differences were observed in nuclear content between any of the experimental conditions (Figure 9C). However, consistent with our data regarding the effects of $\mathrm{IL}-15 \mathrm{Ra}$ loss on myotube morphology and myogenic ability, cultures lacking IL-15R $\alpha$ displayed significantly less total cellular protein (Figure 9B). These data

A

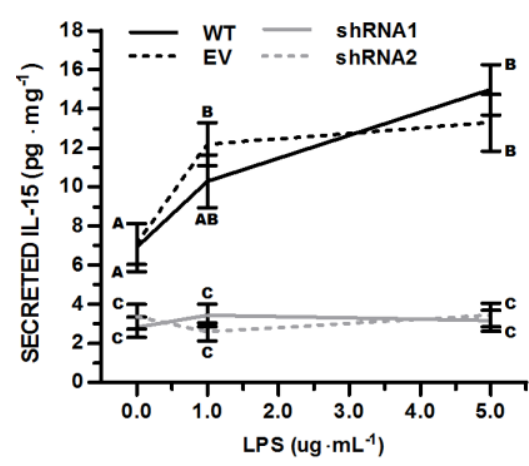

B

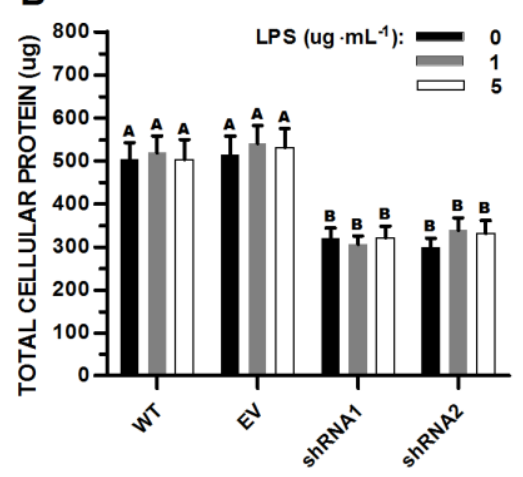

C

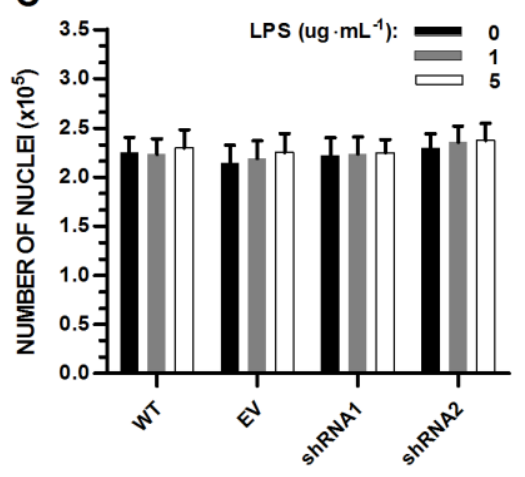

Figure 9. Effects of IL-15Ra loss on IL-15 secretion in vitro.

(A) Treatment of mature WT and EV myotubes with LPS resulted in a significant increase in secreted IL-15. LPS treatment failed to yield a secretory response in cell lines lacking IL-15Ra. Cultures lacking IL-15Ra displayed significantly lower supernatant IL-15 levels under all conditions. (B) Cultures lacking IL-15Ra significantly less total protein content than controls. LPS treatment did not affect the total culture protein content of any cell line. (C) No differences were observed in culture nuclei content under any experimental condition. Data represent mean $\pm S E$ for 4 independent experiments. Letters denote statistically identical means. 
suggest that IL-15Ra may be critical for IL-15 secretion in-vitro and also that LPS may be a potent stimulator of IL-15 secretion in skeletal muscle.

\section{5}

Conditional knockout of IL-15Ra in mouse skeletal muscle:

In order to examine the effects of skeletal muscle IL-15Ra KO on IL-15 secretion in vivo, site specific CRE recombination was used to generate a transgenic mouse model exhibiting conditional loss of IL-15Ra in muscle. Mice were generated carrying LoxP sites flanking exons 2 and 3 of the IL-15Ra gene; the presence of CRE recombinase expression under the muscle creatine kinase promoter (MCK) resulted in recombination at the LoxP sites, yielding effective deletion of exons 2 and 3 specifically in muscle tissue (Figure 10A). Exons 2 and 3 of IL-15Ra are essential for IL-15 binding, and its absence has been previously shown to result in a nonfunctional protein unable to interact with IL-15. PCR targeting the recombined IL-15Ra gene confirmed selective recombination in skeletal and heart muscle tissue in mice expressing MCK driven CRE. The 610 bp product denotes the presence of the LoxP floxed IL-15Ra allele, with the 392 bp product only being possible after recombination (Figure 10B). RT-PCR using skeletal muscle mRNA targeting the specific exons of IL-15Ra was performed to determine exonspecific expression of IL-15Ra following recombination. Primers were designed to produce amplicons of IL-15Ra mRNA encoded by the following regions of the IL-15Ra gene: exons 1-4, 2-3, 4-8, 5-8, 6-8, 7-8, and 8-9. CRE- littermate controls produced all expected amplicons, indicating the expression of all 9 exons of IL-15Ra. Amplicons spanning exons 1-4 and 2-3 were absent in MCK CRE+ mice, with the remaining amplicons remaining present, indicating a loss of expression of exons 1-3. An identical pattern of exonic expression was observed in muscle tissue from the IL-15Ra global KO mouse (Figure 10C). RT-PCR targeting exons 2-3 of IL-15Ra was performed in various tissues isolated from CRE+ mice, confirming that ablated mRNA expression of these exons was a muscle specific effect (Figure 10D).

In an attempt to characterize IL-15Ra expression at the protein level, ELISA targeting IL$15 \mathrm{R} \alpha$ was performed in lysates prepared from muscle, lung, kidney, and spleen as well as in serum. No significant differences in IL-15Ra expression between MCK CRE+ and MCK CREmice were observed in any tissue type assayed, including muscle (Supplementary Figure 1A). Based on the exonic expression profile observed in the MCK CRE+ mouse, this may be attributed to the presence of a truncated protein product, as exons 4-9 still appear to be 
A

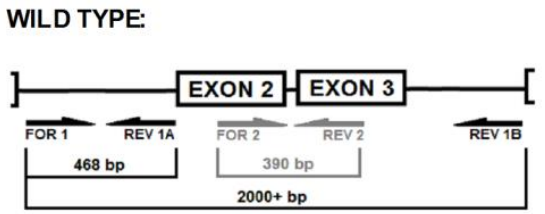

B

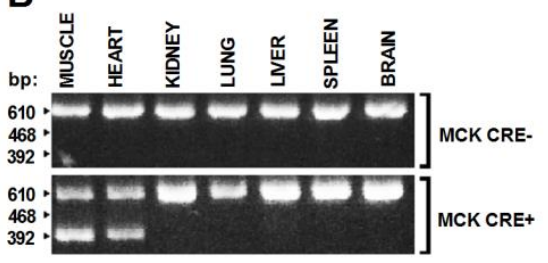

D

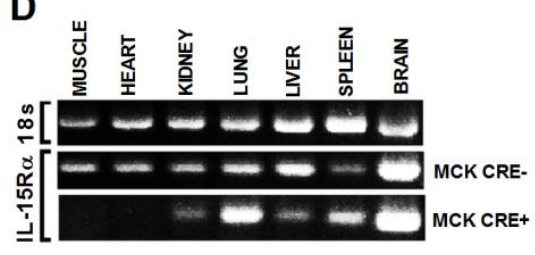

IL-15R $\alpha$ FLOX / MCK CRE- :

IL-15R $\alpha$ FLOX / MCK CRE+ :
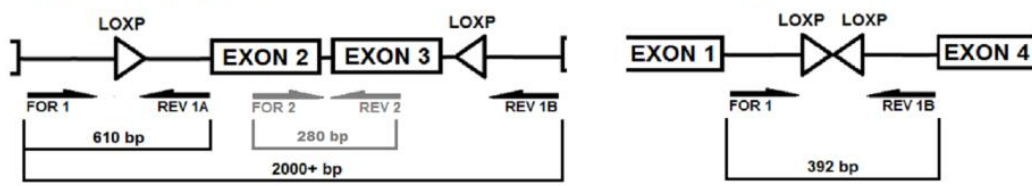

C

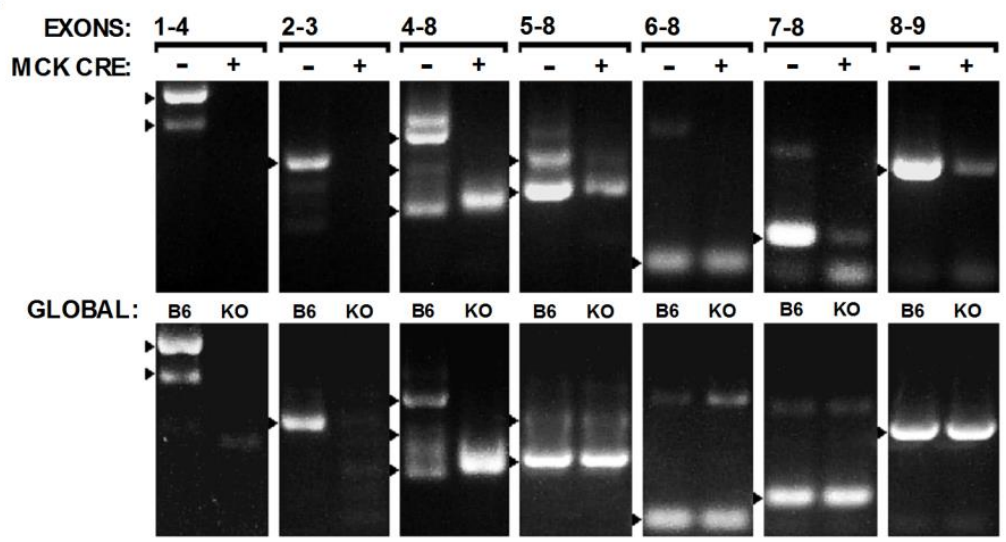

Figure 10. Molecular characterization of muscle-specific IL-15Ra KO mice.

(A) Location of LoxP sites and primers. Forward primer 1 and reverse primer $1 \mathrm{~A}$ target genomic DNA and produce a 468 bp product when amplifying a wild type IL-15R a allele, or 610 bp product when LoxP sites are present. Forward primer 1 and reverse primer 1B target genomic DNA and produce a $2000+$ bp product which isn't detectable by low-fidelity PCR when amplifying a nonrecombinated IL-15Ra allele, and a detectable 392 bp product when amplifying a recombined IL15Ra allele. Forward primer 2 and reverse primer 2 target IL-15Ra cDNA and produce a $280 \mathrm{bp}$ amplicon in the presence of IL-15Ra transcript containing exons 2 and 3. (B) PCR using forward primer 1 , reverse primer $1 \mathrm{~A}$, and reverse primer $1 \mathrm{~B}$ produces a $610 \mathrm{bp}$ product in MCK CRE- mice indicating the homozygous presence of LoxP sites in all assayed tissues, and fails to produce the $392 \mathrm{bp}$ product corresponding to a recombined IL-15Ra. Identical PCR in MCK CRE+ mice produces a $610 \mathrm{bp}$ product in all tissues along with a $392 \mathrm{bp}$ product specifically in skeletal muscle and heart, indicating recombination. (C) RT-PCR targeting the individual exons of IL-15Ra in cDNA obtained from muscles of MCK CRE+ mice failed to produce amplicons spanning exons 1-4 and exons 2-3. A similar pattern of expression was observed in the IL-15Ra global KO mouse. Arrowheads represent predicted products. (D) RT-PCR targeting IL-15Ra in various tissues fails to produce a product in skeletal muscle and cardiac tissue obtained from MCK CRE+ mice.

expressed on the transcriptional level. Accordingly, no significant differences were observed in serum IL-15Ra (Supplementary Figure 1B).

\section{6}

Effects of IL-15Ra loss on IL-15 transcription and secretion in vivo:

In order to determine whether the loss of IL-15Ra specifically in skeletal muscle resulted in alterations to IL-15 expression, RT-PCR was performed. MCK CRE+ mice lacking IL-15R $\alpha$ 
conditionally in skeletal muscle displayed a significant increase in quadriceps IL-15 mRNA expression, similar to what was previously reported with IL-15R $\alpha$ loss in the global KO mouse (Figure 11A). ELISA targeting IL-15 in serum was performed to determine whether this increase in IL-15 mRNA expression resulted in changes in circulating IL-15. No significant differences in serum IL-15 were observed between MCK CRE+ and littermate controls, suggesting that loss of IL-15Ra specifically in skeletal muscle does not result in an increase in a substantial increase in IL-15 secretion in vivo (Figure 11B).

\section{A}

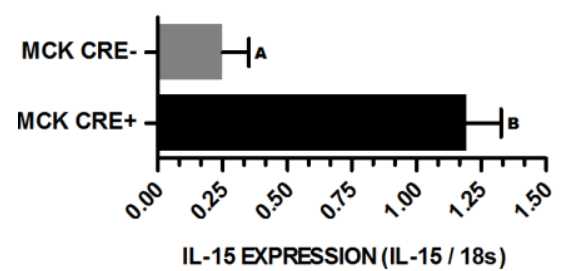

B

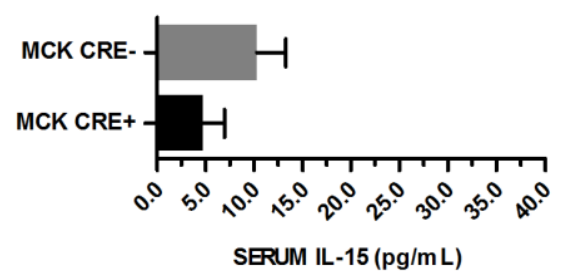

C

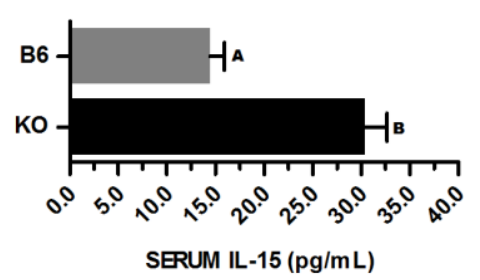

Figure 11. Effects of muscle specific IL-15Ra loss on IL-15 expression in-vivo.

(A) RT-PCR targeting IL-15 in skeletal muscle reveals a greater abundance of IL-15 transcript in muscles of MCK CRE+ mice in comparison to MCK CRE- controls. (B) ELISA targeting serum IL-15 revealed no significant differences in circulating IL-15 between the muscle specific IL-15Ra KO mouse and littermate controls. (C) Identical ELISA in serum obtained from the IL-15Ra global KO mouse shows significant increases in serum IL-15 in comparison to B6-129 controls. Data are represented as mean $\pm S E$ with letters denoting statistically identical means. 


\section{Chapter 4.}

\section{Discussion:}

Loss of IL-15Ra in the IL-15Ra global knock-out mouse has been shown to promote remodeling of skeletal muscle towards an oxidative phenotype characterized by fatigue resistance and a substantial increase in mitochondrial density, changes which would be deemed positive in conditions of mitochondrial dysfunction. However, the mechanisms by which loss of IL-15Ra in the global knockout results in pro-oxidative muscle changes was unclear, as IL-15 signaling in skeletal muscle has been virtually uncharacterized. It was previously suggested that loss of IL-15Ra in the global KO mouse results in an increase in muscle IL-15 secretion, that this increase in secreted IL-15 acts on skeletal muscle in an autocrine fashion to increase IL-15 signal transduction, and that this increase in IL-15 signaling directly results in pro-oxidative changes. However, the ubiquitous absence of IL-15Ra in the IL-15Ra global KO mouse made it difficult to determine whether the oxidative changes observed in skeletal muscle were a direct result of IL-15Ra loss in muscle tissue alone, or whether changes in non-muscle tissues played a contributing role. Additionally, the previously suggested mechanistic explanation presents several paradoxes to the IL-15 signaling paradigms which have been established within the immune system. Thus, our aim was to further explore the possible mechanisms responsible for the pro-oxidative muscle changes observed in the global IL-15R $\alpha \mathrm{KO}$ mouse, and determine the plausibility of the previously proposed mechanism. It was hypothesized that loss of IL-15Ra in myogenic cultures and in-vivo in a muscle-specific fashion would increase IL-15 secretion. It was also hypothesized that cultures lacking IL-15R $\alpha$ would demonstrate a maintained ability to respond to IL-15 in the presence of sufficiently elevated concentrations. Lastly, it was hypothesized that myogenic cultures treated with IL-15 would exhibit evidence of increases in mitochondrial density similar to what was observed in the skeletal muscle of the global IL-15R $\alpha$ KO mouse. Collectively, the data suggest that IL-15 may have the capacity to directly stimulate pro-oxidative changes in skeletal muscle, and that the changes observed in the skeletal muscle of the global IL-15Ra KO mouse may be attributed directly to increased response to IL-15. However, contradicting what was observed in the global IL-15Ra KO mouse, the data suggest that loss of IL-15Ra in skeletal muscle impairs IL-15 secretion as well as the ability to respond to IL-15, suggesting that a confound in the global IL-15Ra KO mouse, such as immunodeficiency, results in an altered ability to secrete and respond to IL-15. 
It was previously suggested that loss of IL-15Ra in skeletal muscle directly results in an increase in IL-15 secretion. However, here we show that knockout of IL-15Ra in myogenic cultures resulted in a significantly impaired ability to secrete IL-15, even in the presence of proinflammatory stress. In agreement with this observation, our conditional KO of IL-15Ra in mouse skeletal muscle failed to yield an increase in circulating IL-15. These observations are consistent with previous studies using other cell types which have suggested that IL-15Ra is essential for IL-15 secretion, ${ }^{18,20,21,76}$ and suggest that IL-15R $\alpha$ is equally as important in skeletal muscle. Interestingly, we novelly showed an ability of cultured skeletal muscle to respond to LPS stimulation with IL-15 secretion. This observation is constant with studies in lymphoid and epithelial tissues which have shown a similar IL-15 secretory response to LPS. ${ }^{77-82}$ Due to the role that IL-15 plays as an inflammatory mediator and immune cell chemo-attractant in other tissues, ${ }^{53,83,84}$ it is not surprising that pro-inflammatory stimuli would result in IL-15 secretion from muscle as well. However, it is interesting in respect to the potential function of IL-15 in skeletal muscle, which is still ambiguous. Muscle IL-15 secretion is believed to be stimulated by exercise $^{85-89}$; our observations linking muscle IL-15 secretion to pro-inflammatory stimuli, taken with the role that IL-15 has been shown to play in potentiating inflammation in conditions such as arthritis, ${ }^{53}$ suggest that it may be possible that IL-15 is released by skeletal muscle following exercise as an inflammatory response and acts to modulate post-exercise muscle inflammation.

It was previously suggested that IL-15 acts directly on skeletal muscle to drive prooxidative remodeling. Our attempt to explore the chronic effects of IL-15 signaling on mitochondrial density in myogenic cultures was confounded by alterations in myotube morphology. Chronic IL-15 treatment during differentiation appeared to enhance myogenesis, resulting in a myotube phenotype characterized by increased myotube diameter, total protein accretion, and transcriptional expression of $\mathrm{MYH}$. This is consistent with other in-vitro studies suggesting an anabolic role for IL-15 in skeletal muscle. ${ }^{90,91}$ Concurrently, loss of IL-15Ra had an opposite effect, with cultures lacking IL-15R displaying a lower degree of myogenic fusion, smaller myotubes diameters, decreased protein accumulation, and lower expression of $\mathrm{MYH}$ in response to differentiative stimuli. As a whole, these data suggest a critical role for IL-15 and IL$15 R \alpha$ in the differentiative process in-vitro; however, the manner by which this occurs is unclear. This may be a result of the ability of IL-15 to mediate signaling pathways which are commonly considered inflammatory. There is prior evidence which implicate traditionally inflammatory pathways such as p38 MAPK and NF-KB as being involved in the process of skeletal muscle differentiation. Enhanced p52-RelB NF-KB heterodimer activity induced by overexpression of 
IKKa, for example, has been shown to enhance myogenesis in a mechanism that appears to be dependent on positive regulation of mitochondrial biogenesis. ${ }^{92}$ Interestingly, IL-15 treatment has been shown to potently activate NF-KB pathways in various immune cells as well as bone marrow progenitor populations. ${ }^{89,93}$ Thus, IL-15 mediated stimulation of NF-KB pathways which influence mitochondrial biogenesis during differentiation is a potential explanation for the role that IL-15 appears to play in influencing myogenesis in-vitro. However, it is important to note that this effect of IL-15Ra loss on muscle differentiation only appears to occur in vitro, as skeletal muscle in both the global and muscle specific IL-15Ra KO mouse models does not appear to be developmentally impaired. ${ }^{16}$

Due to the effects of chronic IL -15 treatment in altering myotube morphology confounding measures of mitochondrial density, we alternatively stimulated mature myotubes with IL-15 acutely and assessed the response of the pro-oxidative genes PPARס and PGC-1a, to determine whether IL-15 can directly act on skeletal muscle in a pro-oxidative manner as previously suggested. We observed induction of both PGC-1 $\alpha$ and PPARס following acute treatment with IL-15. These data agree with previous in-vitro observations which have shown

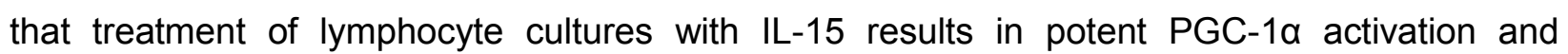
increases in mitochondrial DNA content. ${ }^{94}$ Furthermore, these data also support in vivo studies which have shown associative data linking pro-oxidative muscle remodeling to systemic increase in IL-15, ${ }^{60,95}$ including those using the global IL-15Ra KO mouse, ${ }^{15,16}$ and suggest that the muscle changes observed in these models are indeed a result of a direct effect of IL-15 on skeletal muscle. However, the precise mechanism by which IL-15 results in these changes remains unclear. This result was interesting with regards to what was observed with chronic IL15 treatment in that another PGC-1 isotype, PGC-1 $\beta$, has been shown to be essential for developmental mitochondrial biogenesis and effective myogenic differentiation. ${ }^{96}$ If IL-15 acts on PGC-1 $\beta$ in similar manner, this may also offer another possible explanation as to why altering IL-15 during differentiation appears to influence myogenesis.

Our data regarding the effects of chronic IL-15 treatment during myogenic differentiation provided somewhat conflicting results in comparison to what we observed when treating mature myotubes acutely with IL-15. Chronic IL-15 treatment during differentiation resulted in a hypertrophic myotube phenotype characterized by increased expression of MYH, constituting what appears to be an anabolic effect, while acute treatment of mature myotubes induced prooxidative gene expression, a seemingly opposing effect. One potential explanation for this paradox, is the differential expression of pro-oxidative genes during the myogenic process. Both 
PPARס and PGC-1 $\alpha$ are virtually unexpressed in myogenic cultures for up to the first 3 days of differentiation. However, both transcripts and their associated proteins are readily detectable in mature myotubes. ${ }^{96}$ Thus, if IL-15 targets PGC-1 $\alpha$ and PPAR $\delta$ in mature skeletal muscle, the fact that these proteins are not expressed during early differentiation may mean that IL-15 treatment during myogenesis results in an alternative gene activation program in their absence.

It was previously suggested that skeletal muscle could still respond to IL-15 in the absence of IL-15Ra. To address this hypothesis, myogenic cultures lacking IL-15Ra were chronically treated with IL-15 during differentiation to determine if they could undergo a similar morphologic response as to what was observed in cultures expressing IL-15Ra. Cultures lacking IL-15Ra failed to respond to IL-15 treatment in terms of myotube diameter, total protein accretion, or MYH expression, even at significantly higher doses than those which yielded a response in controls. This would suggest that loss of IL-15R $\alpha$ disrupts IL-15 response in skeletal muscle. These results are strongly consistent with what is observed in terms of IL-15 signaling in the immune system, with the loss of IL-15R $\alpha$ resulting in a significant decrease in the affinity of IL-15 for its signaling receptors, effectively ablating IL-15 signaling. ${ }^{19,21,22}$

Taken as whole, these data provide further insight into the mechanisms responsible for the pro-oxidative muscle changes observed in the global IL-15Ra mouse. Our data regarding the effects of acute IL-15 treatment on pro-oxidative gene expression in myogenic cultures, along with previous reports of oxidative muscle remodeling in transgenic mouse models of IL-15 overexpression, ${ }^{59}$ support the hypothesis that the changes observed in the skeletal muscle of the global $\mathrm{KO}$ mouse are driven by an increase in IL-15 signaling at the muscle. However, in contradiction, our data regarding the effects of IL-15Ra loss on IL-15 response in-vitro suggest that IL-15Ra is essential in the ability of skeletal muscle to respond to IL-15. Furthermore, our data regarding the effects of IL-15Ra loss on IL-15 secretion suggest that IL-15Ra is needed for IL-15 secretion from skeletal muscle, contradicting the hypothesis that loss of IL-15Ra in the global $\mathrm{KO}$ mouse results in an increase in IL-15 secretion from muscle. Thus, our findings regarding secretion, as well as those previously reported in non-muscle tissues, make it difficult to explain the increase in circulating IL-15 which is observed in the IL-15Ra global KO mouse (Figure 12). It is interesting to note that the global model of IL-15Ra loss has been previously characterized as having a moderatly compromised immune system, characterized by lymphopenia and decreased NK cell counts. ${ }^{97}$ However, neither our in-vitro or in-vivo models of muscle specific IL-15Ra loss account for a similar immune alteration. In our in-vitro experiments, immune system interactions were eliminated, and due to the presence of IL-15Ra in the immune 
Figure 12. Results provide contradictory evidence regarding the currently proposed mechanism of pro-oxidative muscle remodeling with loss of IL-15Ra.

(1) Loss of skeletal muscle IL-15Ra both in-vivo and in-vitro failed to result in increased IL-15 secretion, suggesting that loss of IL-15Ra alone is not enough to drive an increase in IL15 secretion. (2) Loss of IL-15Ra ablated the ability of myogenic cultures to respond to $\mathrm{IL}-15$, suggesting that IL-15Ra plays a critical role in muscle IL-15 signal transduction. (3) Treatment of myogenic cultures with IL-15 resulted in induction of PGC-1 $1 \alpha$ and PPARס, suggesting that IL-15 can act directly on skeletal muscle to promote pro-oxidative changes.

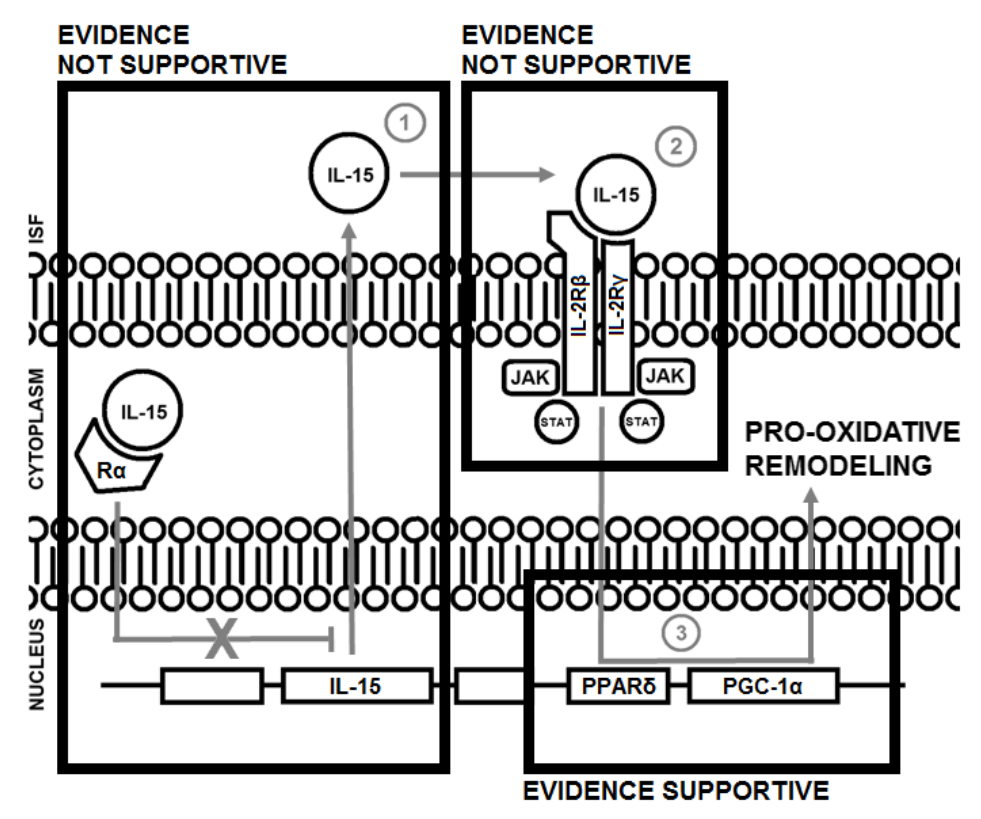

system in the muscle specific IL-15Ra KO, the immune system fails to exhibit similar deficiencies as to what have been observed in the global $\mathrm{KO}$, as total lymphocyte counts and NK cell counts do not appear to be impacted (Supplementary Figure 2). Thus it is possible that the immune deficiencies in the global IL-15Ra KO result in an enhanced ability to both secrete and respond to IL-15 in an attempt to reconstitute immune homeostasis. This provides a likely explanation regarding the contradictions which exist between our models of muscle specific IL$15 \mathrm{Ra}$ loss and what is observed in the IL-15Ra global KO in terms of IL-15 secretion and response. This represents an intriguing scenario, in that IL-15 is typically produced by peripheral tissues in response to an immune challenge such as the presence of pathogen or damage associated molecules to stimulate the maturation of NK cells and promote T-lymphocyte survival. ${ }^{82,98-100}$ If it holds true that the IL-15 secretion is enhanced in the IL-15Ra global KO mouse in response to immune deficiency, it would constitute a novel scenario in which IL-15 secretion is upregulated in the absence of an immune challenge or inflammatory stimulus, and would furthermore suggest the existence of an uncharacterized feedback loop existing between peripheral tissues and the immune system which acts to regulate IL-15 levels with respect to basal immune status.

Collectively, these data provide additional perspective regarding the mechanisms responsible for the oxidative changes observed in the IL-15Ra global KO mouse, as well as novel insight regarding IL-15 signaling in skeletal muscle. These data show some evidence to support the previous hypothesis that the mitochondrial changes observed in the IL-15Ra global 
KO mouse are directly driven by increased autocrine IL-15 signaling, and that IL-15 has the capacity to act directly on skeletal muscle to promote pro-oxidative changes. However, these data suggest that the increases in circulating IL-15 observed in the IL-15Ra global KO mouse with loss of IL-15Ra may constitute a phenomenon driven by a confounding variable such as immunodeficiency, and that loss of IL-15Ra in skeletal muscle alone does not result in an enhanced ability to secrete IL-15 as previously proposed. Furthermore, these data suggest that IL-15 signaling paradigms in skeletal muscle are similar to those which are observed in the immune system, where IL-15R $\alpha$ is essential in the ability to secrete and respond to IL-15. Due to the positive mitochondrial changes observed in the IL-15Ra global KO mouse and other models of systemically elevated IL-15, along with this new evidence of a direct pro-oxidative action of IL-15 in skeletal muscle, the mechanisms by which IL-15 may act to influence oxidative properties in skeletal muscle warrant further investigation, as IL-15 may prove to be a therapeutically exploitable molecule in conditions of mitochondrial dysfunction. 


\section{Chapter 5.}

\section{Experimental procedures:}

\section{1}

Animals:

Mice with LoxP sites flanking exons 2 and 3 of the IL-15Ra gene were obtained as a generous gift from Dr. Averil Ma, University of California San Francisco. Transgenic mice carrying the CRE recombinase gene under the control of the muscle creatine kinase promoter were obtained from Jackson Laboratories (stock number 006475). Global IL-15RaKO mice (stock no. 003723) and B6129 background control mice (stock no. 101045) were obtained from Jackson Laboratories at 8 weeks of age and were used between 10 and 12 weeks of age to maintain consistency with our previously published data ${ }^{16}$. Mice were housed in the animal vivarium at West Virginia University at $22^{\circ} \mathrm{C}$ under a 12-hour light/12-hour dark cycle and received food and water ab libitum. All animal experiments were approved by the Institutional Animal Care and Use Committee at West Virginia University (ACUC\#: 11-0804).

\section{2}

\section{Generation of muscle-specific IL-15Ra KO mice:}

A three-step breeding process was utilized to generate a skeletal and cardiac muscle specific IL-15Ra KO mouse line. In step one of the breeding process, breeding pairs of mice heterozygous for the LoxP-floxed IL-15Ra allele were used to generate IL-15Ra flox homozygous mice at a frequency of approximately $25 \%$. In step two, MCK-CRE hemizygous mice were mated with IL-15Ra flox homozygous mice to obtain IL-15Ra flox heterozygous mice carrying MCK CRE. In step three, IL-15Ra flox heterozygous mice carrying MCK CRE were mated with IL-15Ra flox homozygous mice to obtain IL-15R $\alpha$ flox homozygous mice carrying MCK CRE, which represent the muscle-specific KO experimental mouse line, and IL-15Ra flox homozygous mice lacking MCK CRE, which were used as littermate controls. Male and female mice were used for experiments between the ages of 10 and 12 weeks.

For genotyping, genomic DNA was isolated from tail snips $(2-4 \mathrm{~mm})$ obtained from each animal upon weaning at 21 days of age. The tissue was digested overnight at $55^{\circ} \mathrm{C}$ in $100 \mathrm{uL}$ of tail lysis buffer (Allele Biotechnology, San Diego, CA). The following morning, tissues were 
checked for sufficient digestion and then returned to the hot block for 15 minutes at $80^{\circ} \mathrm{C}$ to denature the proteinase K. PCR reactions were performed to determine the genotype of animals using specific primers for the floxed IL-15R allele and MCK-CRE (Supplementary Table 1). Amplification was performed using a solution consisting of $9.5 \mathrm{uL}$ nuclease free water, 12.5 uL 2X Taq-Pro Red Complete $1.5 \mathrm{mM} \mathrm{MgCl}_{2}$ master mix (Denville Scientific, Metuchen, $\mathrm{NJ}$ ), $0.5 \mathrm{uL}$ forward primer, $0.5 \mathrm{uL}$ reverse primer, and $2 \mathrm{uL}$ of DNA template to make a $25 \mathrm{uL}$ total reaction volume. Following amplification, each reaction was visualized following gel electrophoresis in $1.5 \%(\mathrm{w} / \mathrm{v})$ agarose gels stained with ethidium bromide.

\section{3}

\section{Analysis of IL-15Ra and IL-15 expression in transgenic mice:}

Analysis of IL-15Ra at the genomic, transcriptional, and translational level was performed in multiple tissues of MCK CRE+ and MCK CRE- mice to fully determine the effects of recombination of exons 2 and 3 of the IL-15Ra gene. The following organs and skeletal muscles were harvested and flash frozen in liquid nitrogen: quadriceps muscle, heart, liver, spleen, kidney, lung, and brain. Genomic DNA was isolated from these tissues using a DNeasy Blood and Tissue kit (Qiagen, Valencia, CA) and RNA was isolated using Trizol reagent (Life Technologies, Grand Island, NY). PCR was performed using isolated DNA to verify the genotyping results obtained from tail snips and also to determine that germline recombination did not occur. RT-PCR was performed in all tissues using isolated RNA to examine tissuespecific expression of IL-15Ra. Quadriceps RNA was used to assess the effects of recombination on exon-specific expression of IL-15Ra in skeletal muscle by performing RT-PCR using primers designed to selectively target the individual exons of IL-15Ra. Semi-quantitative RT-PCR was performed using RNA isolated from quadriceps muscle to assess IL-15 expression. ELISA targeting IL-15Ra in protein isolate was performed to assess the effects of recombination on IL-15Ra protein expression.

\section{4}

\section{Generation of IL-15Ra deficient stable myoblasts:}

Low passage $\mathrm{C}_{2} \mathrm{C}_{12}$ murine myoblasts were used for all experiments and cultured using standard aseptic technique (ATCC, Manassas, VA). Myoblasts were maintained under standard mammalian culture conditions $\left(37^{\circ} \mathrm{C}, 99 \%\right.$ humidity, $\left.5 \% \mathrm{CO} 2\right)$ in a growth media comprised of high glucose Delbecco's Modified Eagle Medium (DMEM)(Life Technologies) supplemented 
with $10 \%$ fetal bovine serum (Atlanta Biologicals, Flowery Branch, GA) and antibiotics (Gibco, Grand Island, NY). Cells were passed via trypsinization using $0.05 \%$ trypsin/EDTA in Hank's buffered saline solution (Life Technologies). For induction of myogenic differentiation, myoblasts were incubated in a differentiation media comprised of high glucose DMEM containing $2 \%$ horse serum (Atlanta Biologicals) and antibiotics. Two commercially available plasmid constructs encoding independent shRNAs against IL-15Ra and a green fluorescence protein reporter (tGFP), along with an empty vector control (OriGene, Rockville, MD), were cloned using TOP-10 E-Coli (Life Technologies) and purified using the Qiagen Maxi-Prep system. Low-passage wild type $\mathrm{C} 2 \mathrm{C} 12$ myoblasts were then transiently transfected with purified plasmid constructs. For transient transfection, cells were seeded in a 6-well plate at a density of $1 \cdot 10^{5}$ cells per well in growth media and incubated overnight. Cells were then transfected using a cationic polymer transfection reagent (TurboFect, Thermo Scientific). 36 hours post-transfection, cells were trypsinized and moved to $10 \mathrm{~cm}$ plates containing growth media supplemented with puromycin (Sigma-Aldrich, St. Louis, MO) at a concentration of $5 \mathrm{ug} \cdot \mathrm{mL}^{-1}$. Cells were grown for 10 days in puromycin, with media being replenished every 72 hours. tGFP-expressing colonies were then transferred to 24-well plates using filter paper cloning discs and growth was continued under selective pressure. Clonally-derived populations which displayed normal growth rates, high tGFP expression, and no visible phenotypical abnormalities were further expanded for experimentation. Final clonally-derived cell lines were screened for RNA expression of IL-15R $\alpha$ and tGFP using semi-quantitative RT-PCR. PCR for tGFP using genomic DNA template was also performed to confirm genomic integration of plasmids.

\section{5}

\section{Assessment of stable cell-line growth rates:}

In order to determine the effects of IL-15Ra loss on myoblast proliferation, doubling time of the generated stable cell lines was assessed. Stable cells as well as a wild type control were seeded in triplicate in growth media at a density of $2 \cdot 10^{4}$ cells per well (counted via hemocytometer) in two identical 12-well plates. Three hours post-seeding, one of the duplicate plates was fixed for 30 minutes at $37^{\circ} \mathrm{C}$ in $10 \%$ neutral buffered formalin (NBF). Following fixation, cells were permeablized for 5 minutes using $0.1 \%$ Triton $X-100$ in PBS, and then incubated for 10 minutes with PBS containing 25ul. $\mathrm{mL}^{-1}$ NucBlue Hoechst 33342 (Life Technologies) to stain nuclei. Nuclear staining intensity was then assessed using a fluorescent plate reader (HT-1000, BioTek, Winooski, VT). For fluorescence quantification, a 29-point per 
well area scan was performed with excitation filters set at $360 \mathrm{~nm}$ and emission filters set at 460 $\mathrm{nm}$. The second of the duplicate plates was fixed, stained, and quantified at 39 hours postseeding. Serial dilutions of a known quantitie of Hoechst-stained cells were used to generate a 7-point standard curve correlating Hoechst fluorescence to myoblast count. For standard curve generation, cells were counted via hemocytometer and serial dilutions of a single cell suspension were seeded in 12-well plates in triplicate. Cells were allowed to attach for 3 hours and then fixed, stained, and quantified as described above. This standard curve was used to estimate the myoblast count at both the three and 39 hour time points (Supplementary Figure 3). The difference between cell count at three and 39 hours was used to calculate the doubling time for each stable cell line.

\section{6}

\section{Chronic treatment of myogenic cultures with IL-15:}

To determine the chronic effects of $\mathrm{IL}-15$ treatment on myotube morphology and mitochondrial density, as well as to determine the effects of IL-15Ra loss on IL-15 response, WT and stable cells were stimulated with IL-15 during myotube formation. Twelve replicates of each stable cell line as well as a wild type control were seeded in 12-well plates at a density of $1 \cdot 10^{5}$ cells per well. Following 24 hours in growth media, cells were switched to differentiation media to induce myotube formation. Each cell genotype was stimulated in triplicate with $0,25,100$, and $400 \mathrm{ng} \cdot \mathrm{mL}^{-1}$ recombinant IL-15 (R\&D Systems, Minneapolis, MN) once daily during 4 days of differentiation. Following four days of differentiation, cultures were either stained to assess morphology and mitochondrial density, lysed for PCR analysis of myosin heavy chain (MYH) expression, or incubated with ponceau to assess protein accretion.

\section{7}

\section{Acute treatment of myogenic cultures with IL-15:}

To determine the effects of acute IL-15 treatment on pro-oxidative gene expression, mature WT myotubes were stimulated with IL-15 and the transcriptional response of prooxidative genes was assessed. Six replicates of WT myoblasts were seeded in growth media at a density of $4 \cdot 10^{5}$ in four identical 6 -well plates. 24 hours post-seeding, confluent myoblasts were exposed to differentiation media for four days, yielding mature myotubes. Triplicate wells of each plate were then treated with either vehicle or $25 \mathrm{ng} \cdot \mathrm{mL}^{-1}$ recombinant IL-15. Plates were then incubated for either $0,1,3$, or 12 hours in the presence of IL-15. Following incubation, RNA 
was isolated and semi-quantitative RT-PCR was performed targeting PGC-1 $\alpha$, PPARס, and MYH. Gene expression of IL-15 and vehicle treated cultures was then compared at each time point.

\section{8}

\section{Assessment of mitochondrial density:}

To determine the effects of chronic IL-15 treatment and IL-15Ra loss on mitochondrial density, chronically IL-15 treated cultures were stained with MitoTracker Deep Red (Life Technologies) to assess mitochondrial mass. Cultures were incubated with differentiation media containing $350 \mathrm{nM}$ MitoTracker for 30 minutes. Following MitoTracker incubation, cultures were fixed for 30 minutes at $37^{\circ} \mathrm{C}$ in $10 \%$ NBF. Following fixation, cells were permeablized for 5 minutes using $0.1 \%$ Tritin X-100 in PBS. Nuclei were then stained with Hoechst and both Mitotracker and Hoechst fluorescence was quantified using a fluorescent plate reader similar to what was previously described by Miyake et al. ${ }^{101}$ Excitation filters of 590 $\mathrm{nm}$ and emission filters of $645 \mathrm{~nm}$ were used to perform a 29-point per well area scan for MitoTracker quantification. The same standard curve utilized for the proliferation assay was used to estimate culture nuclei count from Hoechst fluorescence. MitoTracker RFU was then normalized to nuclei count.

\section{9}

\section{Mitochondrial DNA Content:}

Total DNA (genomic and mitochondrial) was extracted from cell lysate using a DNeasy Blood and Tissue kit (Qiagen) and quantified using a Nano-Drop spectrophotometer (Thermo Scientific, Waltham, MA). TaqMan primers (Life Technologies) targeting the mitochondrial cytochrome-c oxidase subunit II (COXII) gene and nuclear 18S ribosomal RNA (18s) were used to perform real-time qPCR. 20 $\mu$ PCR reactions consisting of TaqMan 10X PCR Master Mix, primers, and $5 \mathrm{ng}$ of total DNA were prepared in a 96-well optical reaction plate and amplified using the Applied Biosystems 7900HT Fast Real-Time PCR system. The cycle threshold (CT) values were used to compare levels of COXII gene to $18 \mathrm{~S}$. 


\subsection{0}

\section{Assessment of myotube morphology:}

To determine the effects of chronic IL-15 treatment and IL-15Ra loss on myotube morphology, myotube diameter and fusion index were assessed in chronically IL-15 treated cultures. Cultures chronically treated with IL-15 were stained with MitoTracker and Hoechst as described above. Following staining, 100x multi-channel fluorescent images were obtained using a Zeiss AxioObserver inverted microscope equipped with a gas argon laser, appropriate filter cubes, and a Zeiss AxioCam MRc5 digital camera (Zeiss, Thornwood, NY). Four random images were obtained per well. For image analysis, any cell containing three or more nuclei was considered to constitute a myotube. To assess myotube diameter, the diameter of every myotube per field was manually measured at its widest width using the measure function of the ImageJ ROI manager (National Institutes of Health, Bethesda, Maryland) and myotube diameter distributions for each experimental condition were constructed. To assess fusion index, the ImageJ cell counter plugin was used to count the number of nuclei contained in myotubes as well as the total number of nuclei in each image. Fusion index was then expressed as the ratio of nuclei contained in myotubes to the total number of nuclei. All image analysis was performed blinded.

\subsection{1}

\section{Measuring IL-15 secretion in vitro:}

To determine the effects of IL-15Ra loss on IL-15 secretion, each stable cell line as well as a wild type control were seeded in 12-well plates at a density of $1 \cdot 10^{5}$ cells per well. Following 24 hours in growth media, cells were switched to differentiation media for four days, yielding mature myotubes. Each cell genotype was then stimulated in quadruplicate with 0,1 , and $5 \mathrm{ug} \cdot \mathrm{mL}^{-1}$ lipopolysaccharide (Sigma-Adrich) in media comprised of high glucose DMEM containing $1 \%$ culture grade bovine serum albumin (BSA)(Sigma-Aldrich). Following 24 hours of LPS stimulation, supernatant was collected and immediately frozen at $-80^{\circ} \mathrm{C}$, and later assayed for secreted IL-15 using ELISA. After supernatant collection, cells were then fixed and Hoechst staining was used to estimate culture nuclei count as described for the proliferation assay. Following Hoechst staining and quantification, total culture protein content was assessed using ponceau staining. Total secreted IL-15 assayed via ELISA was then normalized to total culture protein. 


\subsection{2}

\section{IL-15 and IL-15R $\alpha$ ELISA:}

A custom IL-15-specific ELISA was developed using a commercially available ELISA development kit (R\&D Systems). For measurement of IL-15 in cell culture supernatant, anti-IL15 capture antibody was diluted in PBS at $4.0 \mathrm{ug} \cdot \mathrm{mL}^{-1}$, added to plates at $100 \mathrm{uL}$ per well, and incubated overnight at room temperature. Plates were then washed twice with PBST $(0.05 \%$ Tween20) followed by a wash single wash with PBS. Plates were blocked with $1 \%$ BSA in PBS for one hour at room temperature. Following washing, $100 \mathrm{uL}$ of supernatant or standard (recombinant IL-15 in 1\% BSA DMEM) were added per well and incubated for one hour at room temperature. Following sample incubation, plates were washed, and $100 \mathrm{uL}$ biotinylated anti-IL15 detection antibody (400 $\mathrm{ng} \cdot \mathrm{mL}^{-1}$ in PBS with $1 \% \mathrm{BSA}, 2 \%$ normal goat serum) was added per well. Plates were incubated for 2 hours at room temperature, washed, and incubated with streptavidin HRP in 1\% BSA PBS for 30 minutes at room temperature. Following washing, HRP substrate solution and stop solution was added per manufactures recommendations. Optical density of wells was determined via microplate reader (Epoch, BioTek) by measuring absorbance at $450 \mathrm{~nm}$ with $570 \mathrm{~nm}$ wavelength correction. Four-parameter logistic regression was used to generate a 7-point standard curve and sample IL-15 concentrations were calculated. All samples and standards were assayed in duplicate.

For measurement of IL-15 in serum, the following modifications were made: plates were blocked with $20 \%$ fetal calf serum (Atlanta Biologicals) in PBS, serum samples were diluted 1:10 in $1 \%$ BSA PBS, and standards were diluted in $1 \%$ BSA PBS.

For the assessment of tissue IL-15Ra expression, tissue samples were powdered in liquid nitrogen, solubilized in PBS containing $0.1 \%$ NP-40, and spun at $20,000 \cdot \mathrm{g}$ to pellet insoluble debris. Homogenate protein content was assayed via the DC assay and 100 ug of total protein was assayed once again via custom ELISA.

For ELISA targeting IL-15Ra, the R\&D DuoSet system was once again used to develop a custom assay. Anti-IL-15Ra capture antibody was diluted in PBS at $8.0 \mathrm{ug} \cdot \mathrm{mL}^{-1}$, added to plates at $100 \mathrm{uL}$ per well, and incubated overnight at room temperature. Plates were then washed and blocked with $20 \%$ FCS in PBS for one hour at room temperature. Following washing, $100 \mathrm{uL}$ of sample (100 ug protein isolate in 1\% BSA PBS) or standard (recombinant IL-15Ra in 1\% BSA PBS) were added per well and incubated for one hour at room temperature. 
Following sample incubation, plates were washed, and $100 \mathrm{uL}$ biotinylated anti-IL-15R detection antibody (200 $\mathrm{ng} \cdot \mathrm{mL}^{-1}$ in PBS with $1 \% \mathrm{BSA}, 2 \%$ normal goat serum) was added per well and incubated for 2 hours at room temperature. Colormetric detection was then performed as described for ELISA targeting IL-15.

\subsection{3}

\section{Assessment of total culture protein content:}

Total culture protein was determined using a method modified from Hayner et al. ${ }^{102}$ Fixed and permeablized cultures were incubated with 0.5\% Ponceau S (Acros Organics, Fair Lawn, NJ) in 5\% acetic acid for 30 minutes. Following staining, plates were rinsed twice in $5 \%$ acetic acid and once in distilled water. Bound ponceau was then solubilized in $2.0 \mathrm{M} \mathrm{NaOH}$ for 10 minutes on a rocker plate. $50 \mathrm{uL}$ of solubilized ponceau was then removed from the culture plate and placed into a 96-well microtitre plate for spectrophotometry. Optical density was then determined by measuring absorbance at $550 \mathrm{~nm}$. A 6-point standard curve was generated correlating ponceau absorbance to protein content assessed using the DC assay, and was used to estimate total protein based on 550 absorbance. For standard curve generation, serial dilutions of myoblasts were seeded in duplicate in identical 12-well plates. After allowing one hour for adherence, cells from one plate were solubilized in RIPA buffer (Sigma-Aldrich) and assayed via the DC assay (Bio-Rad, Hercules, CA), while cells from the other identical plate were fixed and assayed via the ponceau staining method described above. 550 absorbance from the ponceau assay was then plotted against DC assay protein content to yield a standard curve (Supplementary Figure 4).

\subsection{4}

\section{RNA Isolation and RT-PCR:}

For both animal tissues and cultured cells, total RNA was isolated using Trizol reagent (Life Technologies) per manufactures recommendations. RNA quantity and quality were assessed using a Nano-Drop 2000 spectrophotometer (Thermo Scientific); the 260/280 ratio for all samples used was between 1.8 and 2.0. Two ug of total RNA was reverse transcribed to make cDNA using a high-capacity reverse transcription kit according to manufacturer's instructions (Life Technologies). Amplification was performed using a solution consisting of 9.5 uL nuclease free water, $12.5 \mathrm{uL} 2 \mathrm{X}$ Taq-Pro Red Complete $1.5 \mathrm{mM} \mathrm{MgCl}_{2}$ master mix (Denville Scientific), $0.5 \mathrm{uL}$ forward primer, $0.5 \mathrm{uL}$ reverse primer, and $2 \mathrm{uL}$ of cDNA to make a $25 \mathrm{uL}$ total 
reaction volume. Following amplification, each reaction was visualized following gel electrophoresis in $1.5 \%(\mathrm{w} / \mathrm{v})$ agarose gels stained with ethidium bromide.

For semi-quantitative experiments, primer pairs for target sequences were co-amplified with primer pairs for $18 \mathrm{~S}$ (Ambion, Austin, TX). The number of PCR cycles was determined in preliminary experiments to ensure analyses were done in the linear range of amplification. PCR band intensity was quantified using the ImageJ gel analysis plugin. Signals for the gene of interest were normalized to the bands for $18 \mathrm{~S}$ that were amplified in the same reaction. Primer sequences and amplification conditions for all RT-PCR can be found in Supplementary Table 1.

\subsection{5}

\section{Statistical analysis:}

All data were quantified and analyzed using the GraphPad Prism 5.0 statistical software package (GraphPad Software Incorporated, La Jolla, CA). All experiments were performed in triplicate or quadruplicate in 3-4 independent experiments $(n=3-4)$, data are presented as mean $\pm \mathrm{SE}$, and the null hypothesis was rejected when $P<0.05$. One or two-way ANOVA with bonferroni post-hoc testing was used where appropriate based on the number of independent variables. 


\section{Chapter 6.}

\section{References:}

1. Lin MT, Beal MF. Mitochondrial dysfunction and oxidative stress in neurodegenerative diseases. Nature. 2006;443(7113):787-795. doi:10.1038/nature05292.

2. Peterson CM, Johannsen DL, Ravussin E. Skeletal muscle mitochondria and aging: a review. J Aging Res. 2012;2012:194821. doi:10.1155/2012/194821.

3. Kujoth GC, Hiona a, Pugh TD, et al. Mitochondrial DNA mutations, oxidative stress, and apoptosis in mammalian aging. Science. 2005;309(5733):481-4.

doi:10.1126/science.1112125.

4. Koves TR, Ussher JR, Noland RC, et al. Mitochondrial overload and incomplete fatty acid oxidation contribute to skeletal muscle insulin resistance. Cell Metab. 2008;7(1):45-56. doi:10.1016/j.cmet.2007.10.013.

5. Patti ME, Corvera S. The role of mitochondria in the pathogenesis of type 2 diabetes. Endocr Rev. 2010;31(3):364-395. doi:10.1210/er.2009-0027.

6. Fermoselle C, Garcia-Arumi E, Puig-Vilanova E, et al. Mitochondrial dysfunction and therapeutic approaches in respiratory and limb muscles of cancer cachectic mice. Exp Physiol. 2013;98(9):1349-1365. doi:10.1113/expphysiol.2013.072496.

7. Wenz T, Diaz F, Spiegelman BM, Moraes CT. Activation of the PPAR/PGC-1alpha pathway prevents a bioenergetic deficit and effectively improves a mitochondrial myopathy phenotype. Cell Metab. 2008;8(3):249-256. doi:10.1016/j.cmet.2008.07.006.

8. Rona-Voros K, Eschbach J, Vernay A, et al. Full-length PGC-1alpha salvages the phenotype of a mouse model of human neuropathy through mitochondrial proliferation. Hum Mol Genet. 2013. doi:10.1093/hmg/ddt359.

9. Sandri M, Lin J, Handschin C, et al. PGC-1alpha protects skeletal muscle from atrophy by suppressing FoxO3 action and atrophy-specific gene transcription. Proc Natl Acad Sci U S A. 2006;103(44):16260-16265. doi:10.1073/pnas.0607795103.

10. Bonnefont J-PP, Bastin J, Behin A, Djouadi F. Bezafibrate for an inborn mitochondrial beta-oxidation defect. N Engl J Med. 2009;360(8):838-840. doi:10.1056/NEJMc0806334.

11. Mudò G, Mäkelä J, Di Liberto V, et al. Transgenic expression and activation of PGC-1 $\alpha$ protect dopaminergic neurons in the MPTP mouse model of Parkinson's disease. Cell Mol Life Sci. 2012;69(7):1153-65. doi:10.1007/s00018-011-0850-z.

12. Noe N, Dillon L, Lellek V, et al. Bezafibrate improves mitochondrial function in the CNS of a mouse model of mitochondrial encephalopathy. Mitochondrion. 2013;13(5):417-26. doi:10.1016/j.mito.2012.12.003. 
13. Mensink M, Hesselink MKC, Russell a P, Schaart G, Sels J-P, Schrauwen P. Improved skeletal muscle oxidative enzyme activity and restoration of PGC-1 alpha and PPAR beta/delta gene expression upon rosiglitazone treatment in obese patients with type 2 diabetes mellitus. Int J Obes (Lond). 2007;31(8):1302-10. doi:10.1038/sj.ijo.0803567.

14. Wenz T. PGC-1alpha activation as a therapeutic approach in mitochondrial disease. IUBMB Life. 2009;61(11):1051-1062. doi:10.1002/iub.261.

15. Pistilli EE, Guo G, Stauber WT. IL-15Ralpha deficiency leads to mitochondrial and myofiber differences in fast mouse muscles. Cytokine. 2013;61(1):41-45. doi:10.1016/j.cyto.2012.09.025.

16. Pistilli EE, Bogdanovich S, Garton F, et al. Loss of IL-15 receptor alpha alters the endurance, fatigability, and metabolic characteristics of mouse fast skeletal muscles. $J$ Clin Invest. 2011;121(8):3120-3132. doi:10.1172/jci44945.

17. Pistilli EE, Quinn LS. From Anabolic to Oxidative: Reconsidering the Roles of IL-15 and IL-15Ra in Skeletal Muscle. Exerc Sport Sci Rev. 2013;41(2):100-6. Available at: http://www.ncbi.nlm.nih.gov/pubmed/23072822.

18. Mortier E, Woo T, Advincula R, Gozalo S, Ma A. IL-15Ralpha chaperones IL-15 to stable dendritic cell membrane complexes that activate NK cells via trans presentation. $J$ Exp Med. 2008;205(5):1213-25. doi:10.1084/jem.20071913.

19. Lee GA, Liou Y-H, Wang S-W, Ko K-L, Jiang S-T, Liao N-S. Different NK cell developmental events require different levels of IL-15 trans-presentation. J Immunol. 2011;187(3):1212-21. doi:10.4049/jimmunol.1100331.

20. Bergamaschi C, Jalah R, Kulkarni V, et al. Secretion and biological activity of short signal peptide IL-15 is chaperoned by IL-15 receptor alpha in vivo. J Immunol. 2009;183(5):3064-72. doi:10.4049/jimmunol.0900693.

21. Burkett PR, Koka R, Chien M, Chai S, Boone DL, Ma A. Coordinate expression and trans presentation of interleukin (IL)-15Ralpha and IL-15 supports natural killer cell and memory CD8+ T cell homeostasis. J Exp Med. 2004;200(7):825-34. doi:10.1084/jem.20041389.

22. Sandau MM, Schluns KS, Lefrancois L, Jameson SC. Cutting edge: transpresentation of IL-15 by bone marrow-derived cells necessitates expression of IL-15 and IL-15R alpha by the same cells. J Immunol. 2004;173(11):6537-6541.

23. Anderson S, Bankier A, Barrell B. Sequence and organization of the human mitochondrial genome. Nature. 1981;(290):457-465. Available at: http://www.nature.com/nature/journal/v290/n5806/abs/290457a0.html. Accessed November 1, 2013.

24. Bibb MJ, Van Etten R a, Wright CT, Walberg MW, Clayton DA. Sequence and gene organization of mouse mitochondrial DNA. Cell. 1981;26(2 Pt 2):167-180. Available at: http://www.ncbi.nlm.nih.gov/pubmed/7332926. 
25. Bayona-Bafaluy MP, Acin-Perez R, Mullikin JC, et al. Revisiting the mouse mitochondrial DNA sequence. Nucleic Acids Res. 2003;31(18):5349-5355. doi:10.1093/nar/gkg739.

26. Lin J, Handschin C, Spiegelman BM. Metabolic control through the PGC-1 family of transcription coactivators. Cell Metab. 2005;1(6):361-370.

doi:10.1016/j.cmet.2005.05.004.

27. Miwa S, Lawless C, von Zglinicki T. Mitochondrial turnover in liver is fast in vivo and is accelerated by dietary restriction: application of a simple dynamic model. Aging Cell. 2008;7(6):920-923. doi:10.1111/j.1474-9726.2008.00426.x.

28. J.M. B, J.L. T, L. S. Biochemistry. 5th ed. New York: W H Freeman; 2002.

29. Schon E, Manfredi G. Neuronal degeneration and mitochondrial dysfunction. J Clin Invest. 2003;111(3):303-312. doi:10.1172/JCl200317741.Over.

30. Murphy MP. How mitochondria produce reactive oxygen species. Biochem J. 2009;417(1):1-13. doi:10.1042/bj20081386.

31. Murphy MP. Mitochondrial dysfunction indirectly elevates ROS production by the endoplasmic reticulum. Cell Metab. 2013;18(2):145-146. doi:10.1016/j.cmet.2013.07.006.

32. Kussmaul L, Hirst J. The mechanism of superoxide production by NADH:ubiquinone oxidoreductase (complex I) from bovine heart mitochondria. Proc Natl Acad Sci U S A. 2006;103(20):7607-12. doi:10.1073/pnas.0510977103.

33. Kudin AP, Bimpong-Buta NY-B, Vielhaber S, Elger CE, Kunz WS. Characterization of superoxide-producing sites in isolated brain mitochondria. J Biol Chem. 2004;279(6):4127-35. doi:10.1074/jbc.M310341200.

34. Hockenbery DM, Oltvai ZN, Yin XM, Milliman CL, Korsmeyer SJ. Bcl-2 functions in an antioxidant pathway to prevent apoptosis. Cell. 1993;75(2):241-251.

35. Yakes FM, Van Houten B. Mitochondrial DNA damage is more extensive and persists longer than nuclear DNA damage in human cells following oxidative stress. Proc Natl Acad Sci U S A. 1997;94(2):514-9. Available at:

http://www.pubmedcentral.nih.gov/articlerender.fcgi?artid=19544\&tool=pmcentrez\&rende rtype=abstract.

36. Lam M, Dubyak G, Chen L, et al. Evidence that BCL-2 represses apoptosis by regulating endoplasmic reticulum-associated Ca2+ fluxes. Proc Natl Acad Sci U S A. 1994;91(14):6569-6573. Available at: http://www.pubmedcentral.nih.gov/articlerender.fcgi?artid=44244\&tool=pmcentrez\&rende rtype=abstract.

37. Finck BN, Kelly DP. PGC-1 coactivators: inducible regulators of energy metabolism in health and disease. J Clin Invest. 2006;116(3):615-622. doi:10.1172/jci27794. 
38. Puigserver P, Wu Z, Park CW, Graves R, Wright M, Spiegelman BM. A cold-inducible coactivator of nuclear receptors linked to adaptive thermogenesis. Cell. 1998;92(6):82939. Available at: http://www.ncbi.nlm.nih.gov/pubmed/9529258.

39. Goldstein A, Wolfe LA. The elusive magic pill: finding effective therapies for mitochondrial disorders. Neurotherapeutics. 2013;10(2):320-328. doi:10.1007/s13311-012-0175-0.

40. Hondares E, Pineda-Torra I, Iglesias R, Staels B, Villarroya F, Giralt M. PPARdelta, but not PPARalpha, activates PGC-1alpha gene transcription in muscle. Biochem Biophys Res Commun. 2007;354(4):1021-7. doi:10.1016/j.bbrc.2007.01.092.

41. Greer EL, Oskoui PR, Banko MR, et al. The energy sensor AMP-activated protein kinase directly regulates the mammalian FOXO3 transcription factor. J Biol Chem.

2007;282(41):30107-19. doi:10.1074/jbc.M705325200.

42. Zong $\mathrm{H}$, Ren JM, Young $\mathrm{LH}$, et al. AMP kinase is required for mitochondrial biogenesis in skeletal muscle in response to chronic energy deprivation. Proc Natl Acad Sci U S A. 2002;99(25):15983-7. doi:10.1073/pnas.252625599.

43. Schaeffer PJ, Wende AR, Magee CJ, et al. Calcineurin and calcium/calmodulindependent protein kinase activate distinct metabolic gene regulatory programs in cardiac muscle. J Biol Chem. 2004;279(38):39593-603. doi:10.1074/jbc.M403649200.

44. Herzig S, Long $F$, Jhala US, et al. CREB regulates hepatic gluconeogenesis through the coactivator PGC-1. Nature. 2001;413(6852):179-83. doi:10.1038/35093131.

45. Baar K, Wende AR, Jones TE, et al. Adaptations of skeletal muscle to exercise: rapid increase in the transcriptional coactivator PGC-1. FASEB J. 2002;16(14):1879-86. doi:10.1096/fj.02-0367com.

46. Jäger S, Handschin C, St-Pierre J, Spiegelman BM. AMP-activated protein kinase (AMPK) action in skeletal muscle via direct phosphorylation of PGC-1alpha. Proc Natl Acad Sci U S A. 2007;104(29):12017-22. doi:10.1073/pnas.0705070104.

47. Knutti D, Kressler D, Kralli a. Regulation of the transcriptional coactivator PGC-1 via MAPK-sensitive interaction with a repressor. Proc Natl Acad Sci U S A. 2001;98(17):9713-8. doi:10.1073/pnas.171184698.

48. Jeninga EH, Schoonjans K, Auwerx J. Reversible acetylation of PGC-1: connecting energy sensors and effectors to guarantee metabolic flexibility. Oncogene. 2010;29(33):4617-4624. doi:10.1038/onc.2010.206.

49. St-Pierre J, Lin J, Krauss S, et al. Bioenergetic analysis of peroxisome proliferatoractivated receptor gamma coactivators 1alpha and 1beta (PGC-1alpha and PGC-1beta) in muscle cells. J Biol Chem. 2003;278(29):26597-603. doi:10.1074/jbc.M301850200.

50. Leone TC, Lehman JJ, Finck BN, et al. PGC-1alpha deficiency causes multi-system energy metabolic derangements: muscle dysfunction, abnormal weight control and hepatic steatosis. PLoS Biol. 2005;3(4):e101. doi:10.1371/journal.pbio.0030101. 
51. Waldmann TA, Tagaya $\mathrm{Y}$. The multifaceted regulation of interleukin-15 expression and the role of this cytokine in NK cell differentiation and host response to intracellular pathogens. Annu Rev Immunol. 1999;17:19-49. doi:10.1146/annurev.immunol.17.1.19.

52. Kurowska M, Rudnicka W, Kontny E, et al. Fibroblast-like synoviocytes from rheumatoid arthritis patients express functional IL-15 receptor complex: endogenous IL-15 in autocrine fashion enhances cell proliferation and expression of $\mathrm{Bcl}-\mathrm{x}(\mathrm{L})$ and $\mathrm{Bcl}-2$. $J$ Immunol. 2002;169(4):1760-1767. Available at: http://www.ncbi.nlm.nih.gov/pubmed/12165497.

53. Mclnnes IB, al-Mughales J, Field M, et al. The role of interleukin-15 in T-cell migration and activation in rheumatoid arthritis. Nat Med. 1996;2(2):175-182.

54. Malamut G, El Machhour R, Montcuquet N, et al. IL-15 triggers an antiapoptotic pathway in human intraepithelial lymphocytes that is a potential new target in celiac diseaseassociated inflammation and lymphomagenesis. J Clin Invest. 2010;120(6):2131-2143. doi:10.1172/jci41344.

55. Tagaya Y, Burton JD, Miyamoto Y, Waldmann T a. Identification of a novel receptor/signal transduction pathway for IL-15/T in mast cells. EMBO J. 1996;15(18):4928-39. Available at:

http://www.pubmedcentral.nih.gov/articlerender.fcgi?artid=452230\&tool=pmcentrez\&rend ertype $=$ abstract.

56. Giri JG, Kumaki S, Ahdieh M, et al. Identification and cloning of a novel IL-15 binding protein that is structurally related to the alpha chain of the IL-2 receptor. EMBO J. 1995;14(15):3654-3663.

57. Grabstein KH, Eisenman J, Shanebeck K, Rauch C, Srinivasan S, Fung V, Beers C, Richardson J, Schoenborn MA AM. Cloning of a T cell growth factor that interacts with the beta chain of the interleukin-2 receptor. Science (80- ). 1994;264(5161):965-968.

58. He $\mathrm{Y}, \mathrm{Wu} \mathrm{X}, \mathrm{Khan} \mathrm{RS}$, et al. IL-15 receptor deletion results in circadian changes of locomotor and metabolic activity. J Mol Neurosci. 2010;41(2):315-321.

doi:10.1007/s12031-009-9319-z.

59. Quinn LS, Anderson BG, Conner JD, Wolden-Hanson T. IL-15 overexpression promotes endurance, oxidative energy metabolism, and muscle PPARdelta, SIRT1, PGC-1alpha, and PGC-1beta expression in male mice. Endocrinology. 2013;154(1):232-245. doi:10.1210/en.2012-1773.

60. Quinn LS, Anderson BG, Conner JD, Wolden-Hanson T, Marcell TJ. IL-15 is required for postexercise induction of the pro-oxidative mediators PPARס and SIRT1 in male mice. Endocrinology. 2014;155(1):143-55. Available at: http://www.ncbi.nlm.nih.gov/pubmed/24169546.

61. Koka R, Burkett PR, Chien M, et al. Interleukin (IL)-15R[alpha]-deficient natural killer cells survive in normal but not IL-15R[alpha]-deficient mice. J Exp Med. 2003;197(8):977-984. 
62. Waldmann TA. The biology of interleukin-2 and interleukin-15: implications for cancer therapy and vaccine design. Nat Rev Immunol. 2006;6(8):595-601. doi:10.1038/nri1901.

63. Nishimura H, Fujimoto A, Tamura N, Yajima T, Wajjwalku W, Yoshikai Y. A novel autoregulatory mechanism for transcriptional activation of the IL-15 gene by a nonsecretable isoform of IL-15 generated by alternative splicing. Faseb j. 2005;19(1):1928. doi:10.1096/fj.04-2633com.

64. Tagaya $\mathrm{Y}$, Kurys $\mathrm{G}$, Thies TA, et al. Generation of secretable and nonsecretable interleukin 15 isoforms through alternate usage of signal peptides. Proc Natl Acad Sci U S A. 1997;94(26):14444-14449.

65. Lin J, Mlgone T, Tsang M, et al. The Role of Shared Receptor Motifs and Common Stat Proteins in the Generation of Cytokine Pleiotropy. Immunity. 1995;2:331-339.

66. Ring AM, Lin JX, Feng D, et al. Mechanistic and structural insight into the functional dichotomy between IL-2 and IL-15. Nat Immunol. 2012;13(12):1187-1195. doi:10.1038/ni.2449.

67. Rubinstein MP, Kovar M, Purton JF, et al. Converting IL-15 to a superagonist by binding to soluble IL-15R\{alpha\}. Proc Natl Acad Sci U S A. 2006;103(24):9166-9171.

68. Dubois S, Mariner J, Waldmann TA, Tagaya Y. IL-15R?? recycles and presents IL-15 in trans to neighboring cells. Immunity. 2002;17(5):537-547.

69. Budagian V, Bulanova E, Orinska Z, et al. Natural soluble interleukin-15Ralpha is generated by cleavage that involves the tumor necrosis factor-alpha-converting enzyme (TACE/ADAM17). J Biol Chem. 2004;279(39):40368-75. doi:10.1074/jbc.M404125200.

70. Burkett PR, Koka R, Chien M, et al. IL-15R alpha expression on CD8+ T cells is dispensable for T cell memory. Proc Natl Acad Sci U S A. 2003;100(8):4724-4729.

71. He $\mathrm{Y}$, Hsuchou $\mathrm{H}, \mathrm{Wu} \mathrm{X}$, et al. Interleukin-15 receptor is essential to facilitate GABA transmission and hippocampal-dependent memory. J Neurosci. 2010;30(13):4725-4734. doi:10.1523/jneurosci.6160-09.2010.

72. Wu X, He Y, Hsuchou H, Kastin AJ, Rood JC, Pan W. Essential role of interleukin-15 receptor in normal anxiety behavior. Brain Behav Immun. 2010;24(8):1340-1346. doi:10.1016/j.bbi.2010.06.012.

73. Quinn LS, Strait-Bodey L, Anderson BG, Argiles JM, Havel PJ. Interleukin-15 stimulates adiponectin secretion by 3T3-L1 adipocytes: evidence for a skeletal muscle-to-fat signaling pathway. Cell Biol Int. 2005;29(6):449-457. doi:10.1016/j.cellbi.2005.02.005.

74. Alvarez B, Carbo N, Lopez-Soriano J, et al. Effects of interleukin-15 (IL-15) on adipose tissue mass in rodent obesity models: evidence for direct IL-15 action on adipose tissue. Biochim Biophys Acta. 2002;1570(1):33-37. 
75. Quinn LS, Anderson BG, Strait-Bodey L, Stroud AM, Argiles JM. Oversecretion of interleukin-15 from skeletal muscle reduces adiposity. Am J Physiol Endocrinol Metab. 2009;296(1):E191-202. doi:10.1152/ajpendo.90506.2008.

76. Bergamaschi $\mathrm{C}$, Bear $\mathrm{J}$, Rosati $\mathrm{M}$, et al. Circulating IL-15 exists as heterodimeric complex with soluble IL-15Ra in human and mouse serum. Blood. 2012;120(1):e1-8. doi:10.1182/blood-2011-10-384362.

77. Ferretti S, Bonneau O, Dubois GR, Jones CE, Trifilieff A. IL-17, produced by lymphocytes and neutrophils, is necessary for lipopolysaccharide-induced airway neutrophilia: IL-15 as a possible trigger. J Immunol. 2003;170(4):2106-2112. doi:10.1148/119.1.169.

78. Mattei F, Schiavoni G, Belardelli F, Tough DF. IL-15 is expressed by dendritic cells in response to type I IFN, double-stranded RNA, or lipopolysaccharide and promotes dendritic cell activation. J Immunol. 2001;167(3):1179-1187. doi:10.4049/jimmunol.167.3.1179.

79. Ferlazzo G, Pack M, Thomas D, et al. Distinct roles of IL-12 and IL-15 in human natural killer cell activation by dendritic cells from secondary lymphoid organs. Proc Natl Acad Sci U S A. 2004;101(47):16606-16611.

80. Zhang X, Sun S, Hwang I, Tough DF, Sprent J. Potent and selective stimulation of memory-phenotype CD8+ T cells in vivo by IL-15. Immunity. 1998;8(5):591-599. doi:10.1016/S1074-7613(00)80564-6.

81. Doherty TM, Seder RA, Sher A. Induction and regulation of IL-15 expression in murine macrophages. J Immunol. 1996;156(2):735-741.

82. Di Sabatino A, Ciccocioppo R, Cupelli F, et al. Epithelium derived interleukin 15 regulates intraepithelial lymphocyte Th1 cytokine production, cytotoxicity, and survival in coeliac disease. Gut. 2006;55(4):469-477.

83. Jonuleit $\mathrm{H}$, Wiedemann $\mathrm{K}$, Müller $\mathrm{G}$, et al. Induction of IL-15 messenger RNA and protein in human blood-derived dendritic cells: a role for IL-15 in attraction of T cells. J Immunol. 1997;158(6):2610-2615.

84. Wilkinson PC, Liew FY. Chemoattraction of human blood T lymphocytes by interleukin15. J Exp Med. 1995;181(3):1255-1259.

85. Louis E, Raue U, Yang Y, Jemiolo B, Trappe S. Time course of proteolytic, cytokine, and myostatin gene expression after acute exercise in human skeletal muscle. J Appl Physiol. 2007;103(5):1744-1751. doi:10.1152/japplphysiol.00679.2007.

86. Tamura Y, Watanabe K, Kantani T, Hayashi J, Ishida N, Kaneki M. Upregulation of circulating IL-15 by treadmill running in healthy individuals: is IL-15 an endocrine mediator of the beneficial effects of endurance exercise? Endocr J. 2011;58(3):211-215. 
87. Riechman SE, Balasekaran G, Roth SM, Ferrell RE. Association of interleukin-15 protein and interleukin-15 receptor genetic variation with resistance exercise training responses. J Appl Physiol. 2004;97(6):2214-2219. doi:10.1152/japplphysiol.00491.2004.

88. Yang $\mathrm{H}$, Chang $\mathrm{J}$, Chen $\mathrm{W}$, et al. Treadmill exercise promotes interleukin 15 expression in skeletal muscle and interleukin 15 receptor alpha expression in adipose tissue of highfat diet rats. Endocrine. 2013;43(3):579-585.

89. Nielsen AR, Mounier R, Plomgaard P, et al. Expression of interleukin-15 in human skeletal muscle effect of exercise and muscle fibre type composition. $J$ Physiol. 2007;584(Pt 1):305-312.

90. Furmanczyk PS, Quinn LS. Interleukin-15 increases myosin accretion in human skeletal myogenic cultures. Cell Biol Int. 2003;27(10):845-851.

91. Quinn LS, Anderson BG, Drivdahl RH, Alvarez B, Argiles JM. Overexpression of interleukin-15 induces skeletal muscle hypertrophy in vitro: implications for treatment of muscle wasting disorders. Exp Cell Res. 2002;280(1):55-63.

92. Bakkar N, Wang J, Ladner KJ, et al. IKK/NF-kappaB regulates skeletal myogenesis via a signaling switch to inhibit differentiation and promote mitochondrial biogenesis. $J$ Cell Biol. 2008;180(4):787-802. doi:10.1083/jcb.200707179.

93. Chenoweth MJ, Mian MF, Barra NG, et al. IL-15 can signal via IL-15Ra, JNK, and NF-KB to drive RANTES production by myeloid cells. J Immunol. 2012;188(9):4149-57. doi:10.4049/jimmunol.1101883.

94. Van der Windt GJ, Everts $\mathrm{B}$, Chang $\mathrm{CH}$, et al. Mitochondrial respiratory capacity is a critical regulator of CD8+ T cell memory development. Immunity. 2012;36(1):68-78. doi:10.1016/j.immuni.2011.12.007.

95. Quinn LS, Anderson BG, Conner JD, Wolden-Hanson T. IL-15 overexpression promotes

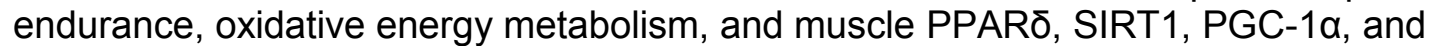
PGC-1 $\beta$ expression in male mice. Endocrinology. 2013;154(1):232-45. Available at: http://endo.endojournals.org.sci-hub.org/content/154/1/232.full.

96. Kraft CS, Lemoine CMR, Lyons CN, et al. Control of mitochondrial biogenesis during myogenesis. 2006:1119-1127. doi:10.1152/ajpcell.00463.2005.

97. Lodolce JP, Boone DL, Chai S, et al. IL-15 receptor maintains lymphoid homeostasis by supporting lymphocyte homing and proliferation. Immunity. 1998;9(5):669-676. doi:10.1016/S1074-7613(00)80664-0.

98. Ozawa A, Tada H, Sugawara $\mathrm{Y}$, et al. Endogenous IL-15 sustains recruitment of IL2Rbeta and common gamma and IL-2-mediated chemokine production in normal and inflamed human gingival fibroblasts. J Immunol. 2004;173(8):5180-5188. 
99. Briard D, Brouty-Boyé D, Azzarone B, Jasmin C. Fibroblasts from human spleen regulate NK cell differentiation from blood CD34(+) progenitors via cell surface IL-15. J Immunol. 2002;168(9):4326-4332.

100. Schluns KS, Nowak EC, Cabrera-Hernandez A, Puddington L, Lefrançois L, Aguila HL. Distinct cell types control lymphoid subset development by means of IL-15 and IL-15 receptor alpha expression. Proc Natl Acad Sci U S A. 2004;101(15):5616-5621.

101. Miyake T, McDermott JC, Gramolini AO. A method for the direct identification of differentiating muscle cells by a fluorescent mitochondrial dye. PLoS One. 2011;6(12):e28628. doi:10.1371/journal.pone.0028628.

102. Hayner NT, Driscoll J, Ferayorni L, Spies-Karotkin G, Jauregui HO. Ponceau S: A sensitive method for protein determination in freshly isolated and cultured cells. $J$ Tissue Cult Methods. 1982;7(2):77-80. doi:10.1007/BF01665914. 


\section{Chapter 7.}

\section{Supplementary Data:}
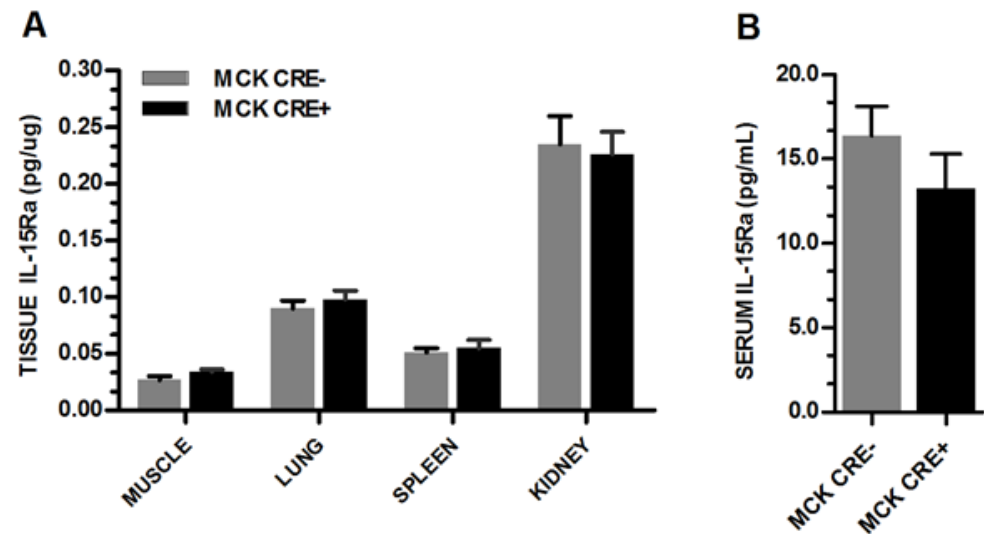

\section{Supplementary Figure 1. Effects of muscle specific IL-15Ra recombination on IL-15Ra}

protein expression.

(A) ELISA revealed no significant differences in IL-15Ra protein expression between tissues obtained from the muscle-specific IL-15R $\alpha$ KO mouse and those obtained from MCK CRE- littermate controls. (B) No differences in circulating IL-15Ra were observed between MCK CRE+ and MCK $\mathrm{CRE}-$ negative mice. Data are represented as mean \pm SE.

A

CD3+ / NK1.1-

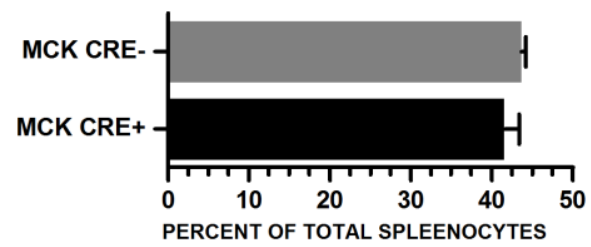

C

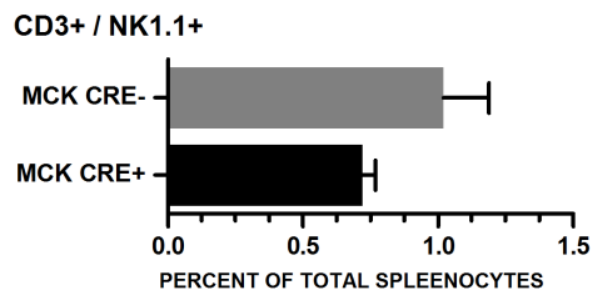

B

CD3- / NK1.1+

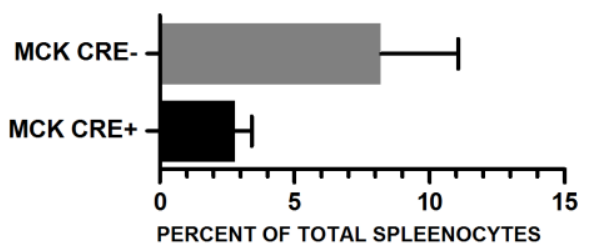

D

NK1.1+

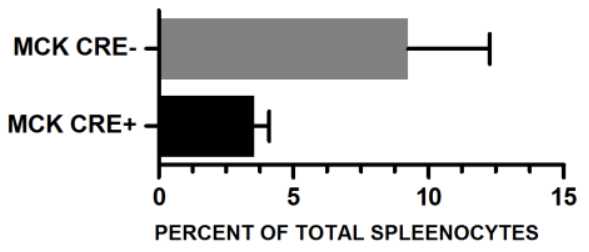

Supplementary Figure 2. Effects of muscle specific IL-15Ra loss on lymphocyte counts. (A) Flow cytometric detection of immunolabeled spleenocytes revealed no significant differences between MCK CRE+ mice and littermate controls in terms of total lymphocyte count (CD3+/NK1.1-) (B) No significant differences were observed in total number of NK cells (CD3-/NK1.1+). (C) No significant differences were observed in number of NK-lymphocytes (CD3+/NK1.1+). (D) No significant differences were observed in number of total NK cells (NK1.1+). Data are represented as mean $\pm S E$. 

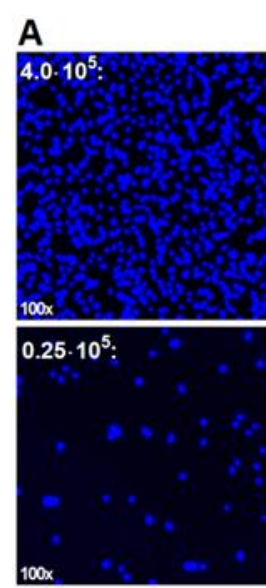

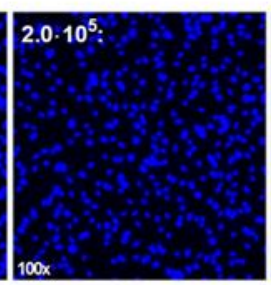

$0.125 \cdot 10^{5}$ :

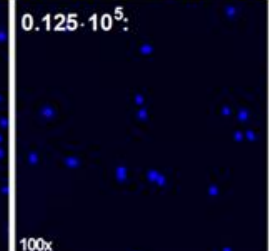

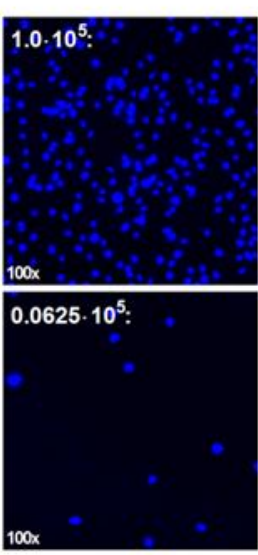
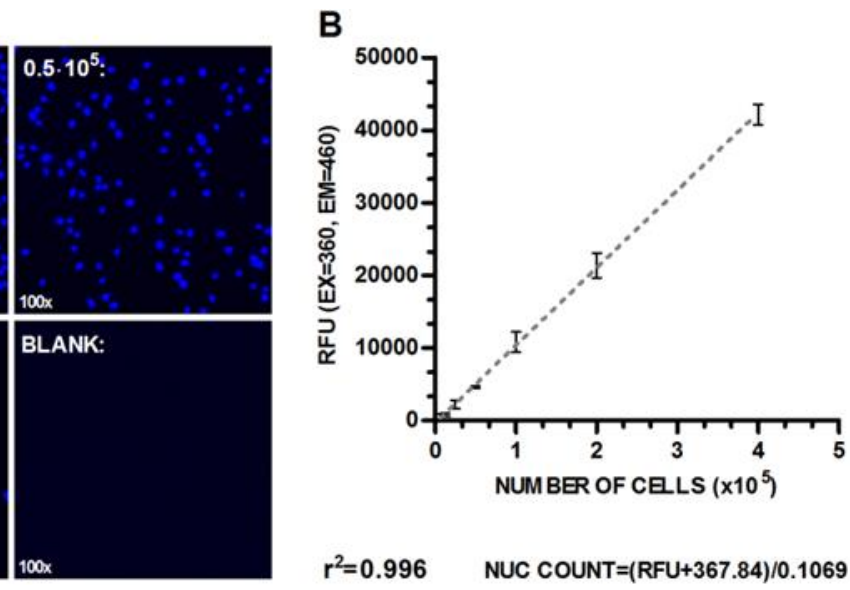

\section{Supplementary Figure 3. Standard curve generation for fluorescent assessment of} culture nuclear content.

(A) Representative images of serially-diluted Hoechst-stained cultures used for standard curve generation. (B) Standard curve used for quantification of nuclear content. There was a strong positive correlation between number of cells seeded and Hoechst fluorescence. Increases in cell number resulted in a ratiometrically similar increase in Hoechst fluorescence. Data are represented as mean $\pm S D$. 
A
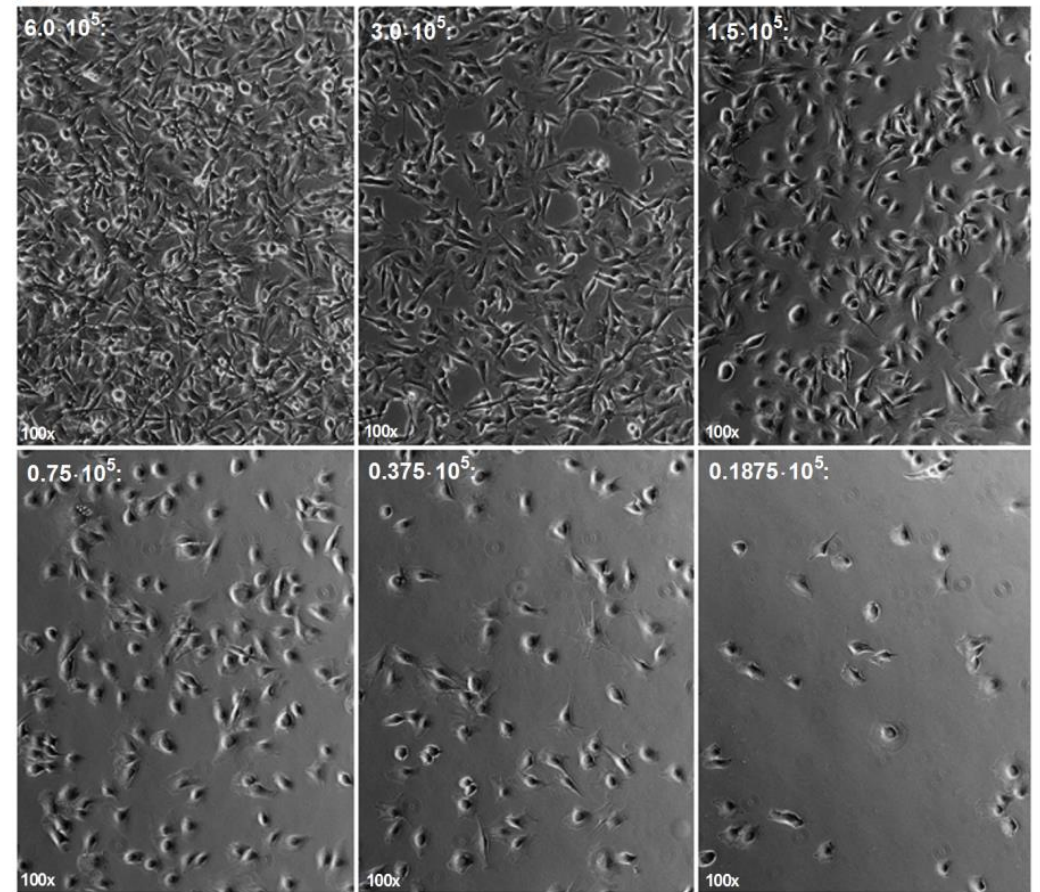

B

NUMBER OF CELLS $\left(x 10^{5}\right)$ :

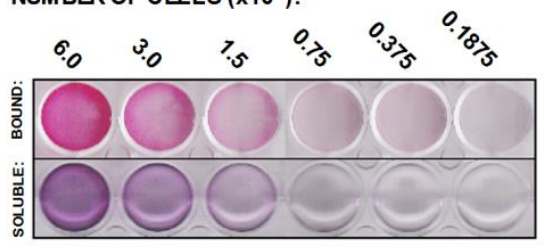

C

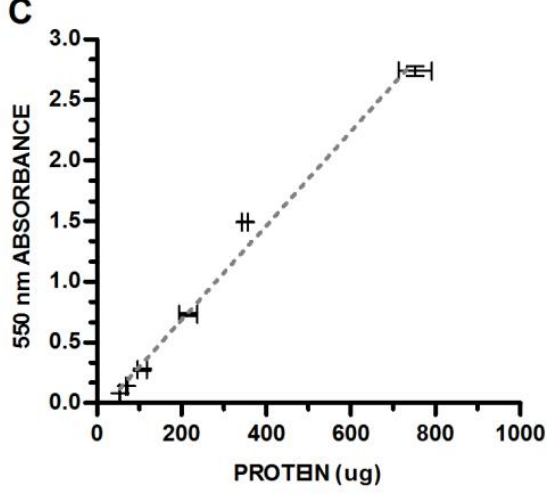

$r^{2}=0.983 \quad$ PROTEIN $($ ug $)=(550$ ABS +0.092$) / 0.004$

\section{Supplementary Figure 4. Standard curve generation for assessment of total cellular protein.}

(A) Representative images of serially-diluted myoblast cultures used for standard curve generation. (B) The top of panel B shows the resultant ponceau staining of serially diluted myoblast cultures. The bottom of panel B shows solubilized ponceau obtained from the staining of serially diluted myoblasts. (C) Standard curve used for quantification of total cellular protein. There was a strong positive correlation between DC assay protein concentration and ponceau absorbance obtained from identical myoblast serial dilutions. Increases in culture protein resulted in a ratiometrically similar increase in ponceau absorbance. Data are represented as mean $\pm S D$. 
Supplementary Table 1. Primers and PCR Conditions.

\begin{tabular}{|c|c|c|c|c|c|c|c|}
\hline TARGET: & SEQUENCE: & ACCESSION: & PRODUCT (bp): & $\mathrm{T}_{\mathrm{M}:}$ & $\mathrm{T}_{\mathrm{A}:}$ & $\mathrm{T}_{\mathrm{E}:}$ & CYCLES: \\
\hline IL-15Ra exons1-4 & $\begin{array}{l}\text { F: 5'-GAATCGTCCGCCCAGAACTT } \\
\text { R: 5'-TGTGAGGTCACCTTTGGTGT }\end{array}$ & $\begin{array}{l}\text { NM_133836.2 } \\
\text { NM_001271497.1 }\end{array}$ & $\begin{array}{l}520 \\
404\end{array}$ & $\begin{array}{l}94^{\circ} \mathrm{C} \\
30 \mathrm{~s}\end{array}$ & $\begin{array}{l}55^{\circ} \mathrm{C} \\
30 \mathrm{~s}\end{array}$ & $\begin{array}{l}72^{\circ} \mathrm{C} \\
45 \mathrm{~s}\end{array}$ & 40 \\
\hline \begin{tabular}{|l} 
IL-15Ra exons 2-3 \\
\end{tabular} & $\begin{array}{l}\text { F: 5'-ATCCGGGGGCTAAAGCAAAA } \\
\text { R: 5'-TTCTTGACCCGGATGTCAGC }\end{array}$ & $\begin{array}{l}\text { NM_008358.2 } \\
\text { NM_001271499.1 } \\
\text { NM_001271500.1 } \\
\text { NM_001271501.1 }\end{array}$ & $\begin{array}{l}280 \\
280 \\
280 \\
280 \\
\end{array}$ & $\begin{array}{l}94^{\circ} \mathrm{C} \\
30 \mathrm{~s}\end{array}$ & $\begin{array}{l}56^{\circ} \mathrm{C} \\
30 \mathrm{~s}\end{array}$ & $\begin{array}{l}72^{\circ} \mathrm{C} \\
45 \mathrm{~s}\end{array}$ & 40 \\
\hline IL-15Ra exons 4-8 & $\begin{array}{l}\text { F: 5'- GACCCCTCCCTAGCTCACTA } \\
\text { R: 5'- CACCAACCAAGAGGACCGAT }\end{array}$ & $\begin{array}{l}\text { NM_008358.2 } \\
\text { NM_133836.2 } \\
\text { NM_001271497.1 } \\
\text { NM_001271499.1 } \\
\text { NM_001271500.1 }\end{array}$ & $\begin{array}{l}370 \\
370 \\
370 \\
271 \\
172\end{array}$ & $\begin{array}{l}94^{\circ} \mathrm{C} \\
30 \mathrm{~s}\end{array}$ & $\begin{array}{l}55^{\circ} \mathrm{C} \\
30 \mathrm{~s}\end{array}$ & $\begin{array}{l}72^{\circ} \mathrm{C} \\
45 \mathrm{~s}\end{array}$ & 40 \\
\hline IL-15Ra exons 5-8 & $\begin{array}{l}\text { F: 5'- AGGCTGACACCATCCCAAAC } \\
\text { R: 5'- CACCAACCAAGAGGACCGAT }\end{array}$ & $\begin{array}{l}\text { NM_008358.2 } \\
\text { NM_133836.2 } \\
\text { NM_001271497.1 } \\
\text { NM_001271498.1 }\end{array}$ & $\begin{array}{l}196 \\
196 \\
196 \\
267\end{array}$ & $\begin{array}{l}94^{\circ} \mathrm{C} \\
30 \mathrm{~s}\end{array}$ & $\begin{array}{l}55^{\circ} \mathrm{C} \\
30 \mathrm{~s}\end{array}$ & $\begin{array}{l}72^{\circ} \mathrm{C} \\
45 \mathrm{~s}\end{array}$ & 40 \\
\hline IL-15Ra exons 6-8 & $\begin{array}{l}\text { F: 5'- CAGTTCCAAAATGACGAAAGTGGC } \\
\text { R: 5'- CCAACCAAGAGGACCGATGT }\end{array}$ & \begin{tabular}{|l} 
NM_008358.2 \\
NM_133836.2 \\
NM_001271497.1 \\
NM_001271498.1 \\
NM_001271499.1 \\
NM_001271500.1 \\
NM_001271501.1
\end{tabular} & $\begin{array}{l}74 \\
74 \\
74 \\
74 \\
74 \\
74 \\
74 \\
74\end{array}$ & $\begin{array}{l}94^{\circ} \mathrm{C} \\
30 \mathrm{~s}\end{array}$ & $\begin{array}{l}55^{\circ} \mathrm{C} \\
30 \mathrm{~s}\end{array}$ & $\begin{array}{l}72^{\circ} \mathrm{C} \\
45 \mathrm{~s}\end{array}$ & 40 \\
\hline IL-15Ra exons 7-8 & $\begin{array}{l}\text { F: 5'- CGAGTACCCTGTCATCGGTT } \\
\text { R: 5'- ATCACAACCCCTGCACCAAC }\end{array}$ & NM_001271498.1 & 103 & $\begin{array}{l}94^{\circ} \mathrm{C} \\
30 \mathrm{~s}\end{array}$ & $\begin{array}{l}55^{\circ} \mathrm{C} \\
30 \mathrm{~s}\end{array}$ & $\begin{array}{l}72^{\circ} \mathrm{C} \\
45 \mathrm{~s}\end{array}$ & 40 \\
\hline IL-15Ra exons 8-9 & \begin{tabular}{|l} 
F: 5'- ACATCGGTCCTCTTGGTTGG \\
R: 5'- GGGCTTTCTCCTGTGTCCAG
\end{tabular} & \begin{tabular}{|l} 
NM_008358.2 \\
NM_133836.2 \\
NM_001271497.1 \\
NM_001271498.1 \\
NM_001271499.1 \\
NM_001271500.1 \\
NM_001271501.1
\end{tabular} & $\begin{array}{l}265 \\
265 \\
265 \\
265 \\
265 \\
265 \\
265\end{array}$ & $\begin{array}{l}94^{\circ} \mathrm{C} \\
30 \mathrm{~s}\end{array}$ & $\begin{array}{l}55^{\circ} \mathrm{C} \\
30 \mathrm{~s}\end{array}$ & $\begin{array}{l}72^{\circ} \mathrm{C} \\
45 \mathrm{~s}\end{array}$ & 40 \\
\hline IL-15 & \begin{tabular}{|l|} 
F: 5'- TCTTCATGGTCCTTGCTGGT \\
R: 5'- GGCCTCTGTTTTAGGGAGACC
\end{tabular} & $\begin{array}{l}\text { NM_001254747.1 } \\
\text { NM_008357.2 }\end{array}$ & $\begin{array}{l}394 \\
394 \\
\end{array}$ & $\begin{array}{l}94^{\circ} \mathrm{C} \\
30 \mathrm{~s}\end{array}$ & $\begin{array}{l}55^{\circ} \mathrm{C} \\
30 \mathrm{~s} \\
\end{array}$ & $\begin{array}{l}72^{\circ} \mathrm{C} \\
45 \mathrm{~s} \\
\end{array}$ & 29 \\
\hline Turbo-GFP & $\begin{array}{l}\text { F: 5'- GATGGGCTACGGCTTCTACC } \\
\text { R: 5'- CCTCGTAGCGGTAGCTGAAG }\end{array}$ & - & 155 & $\begin{array}{l}94^{\circ} \mathrm{C} \\
30 \mathrm{~s}\end{array}$ & $\begin{array}{l}55^{\circ} \mathrm{C} \\
30 \mathrm{~s}\end{array}$ & $\begin{array}{l}72^{\circ} \mathrm{C} \\
45 \mathrm{~s}\end{array}$ & 35 \\
\hline PGC-1a & $\begin{array}{l}\text { F: 5'- TGGTTGCCTGCATGAGTGTG } \\
\text { R: 5'- AGGGCAATCCGTCTTCATCC }\end{array}$ & NM_008904.2 & 396 & $\begin{array}{l}94^{\circ} \mathrm{C} \\
30 \mathrm{~s}\end{array}$ & $\begin{array}{l}55^{\circ} \mathrm{C} \\
30 \mathrm{~s}\end{array}$ & $\begin{array}{l}72^{\circ} \mathrm{C} \\
45 \mathrm{~s}\end{array}$ & 35 \\
\hline PPar-d & $\begin{array}{l}\text { F: 5'- GTGCAGCGGTGTGGGTAT } \\
\text { R: 5'- CCATGACTGACCCCCACTTG }\end{array}$ & NM_011145.3 & 164 & $\begin{array}{l}94^{\circ} \mathrm{C} \\
30 \mathrm{~s}\end{array}$ & $\begin{array}{l}55^{\circ} \mathrm{C} \\
30 \mathrm{~s}\end{array}$ & $\begin{array}{l}72^{\circ} \mathrm{C} \\
45 \mathrm{~s}\end{array}$ & 34 \\
\hline B-Actin & $\begin{array}{l}\text { F: 5'- ACGTACATGGCTGGGGTGTT } \\
\text { R: 5'- ACAGTTTCACCTGCCCTGAGT }\end{array}$ & NC_000071.6 & 109 & $\begin{array}{l}94^{\circ} \mathrm{C} \\
30 \mathrm{~s}\end{array}$ & $\begin{array}{l}55^{\circ} \mathrm{C} \\
30 \mathrm{~s}\end{array}$ & $\begin{array}{l}72^{\circ} \mathrm{C} \\
45 \mathrm{~s} \\
\end{array}$ & 35 \\
\hline MYH & $\begin{array}{l}\text { F: 5'- AGAAGGAGGAGGCAACTTCTG } \\
\text { R: 5'- ACATACTCATTGCCGACCTTG }\end{array}$ & $\begin{array}{l}\text { NM_001039545.2 } \\
\text { NM_030679.1 } \\
\text { NM_010855.3 }\end{array}$ & $\begin{array}{l}650 \\
650 \\
650\end{array}$ & $\begin{array}{l}94^{\circ} \mathrm{C} \\
30 \mathrm{~s}\end{array}$ & $\begin{array}{l}55^{\circ} \mathrm{C} \\
30 \mathrm{~s}\end{array}$ & $\begin{array}{l}72^{\circ} \mathrm{C} \\
45 \mathrm{~s}\end{array}$ & 30 \\
\hline IL-15Ra Flox & $\begin{array}{l}\text { F: 5'- GGCAGTCAGCAAAGAAAGTTGG } \\
\text { R: 5'- TTCCATCCATTCAGTGCGGC }\end{array}$ & NC_000068.7 & $\begin{array}{l}\text { WT: } 468 \\
\text { Flox: } 610\end{array}$ & $\begin{array}{l}94^{\circ} \mathrm{C} \\
60 \mathrm{~s}\end{array}$ & $\begin{array}{l}61^{\circ} \mathrm{C} \\
60 \mathrm{~s}\end{array}$ & $\begin{array}{l}72^{\circ} \mathrm{C} \\
120 \mathrm{~s}\end{array}$ & 34 \\
\hline CRE Deletion & $\begin{array}{l}\text { F: 5'- GGCAGTCAGCAAAGAAAGTTGG } \\
\text { R: 5'- CGATAAAGGTGGGCATCTACAGC }\end{array}$ & NC_000068.7 & 392 & $\begin{array}{l}94^{\circ} \mathrm{C} \\
60 \mathrm{~s}\end{array}$ & $\begin{array}{l}61^{\circ} \mathrm{C} \\
60 \mathrm{~s}\end{array}$ & $\begin{array}{l}72^{\circ} \mathrm{C} \\
120 \mathrm{~s}\end{array}$ & 34 \\
\hline MCK CRE & $\begin{array}{l}\text { F: 5'- GTGAAACAGCATTGCTGTCACTT } \\
\text { R: 5'- TAAGTCTGAACCCGGTCTGC }\end{array}$ & - & 450 & $\begin{array}{l}94^{\circ} \mathrm{C} \\
30 \mathrm{~s}\end{array}$ & $\begin{array}{l}64^{\circ} \mathrm{C} \\
30 \mathrm{~s}\end{array}$ & $\begin{array}{l}72^{\circ} \mathrm{C} \\
30 \mathrm{~s}\end{array}$ & 35 \\
\hline MCK CRE Int Con & $\begin{array}{l}\text { F: 5'- GTCAGTCGAGTGCACAGTTT } \\
\text { R: 5'- CAAATGTTGCTTGTCTGGTG }\end{array}$ & NC_000080.6 & 200 & $\begin{array}{l}94^{\circ} \mathrm{C} \\
30 \mathrm{~s}\end{array}$ & $\begin{array}{l}64^{\circ} \mathrm{C} \\
30 \mathrm{~s}\end{array}$ & $\begin{array}{l}72^{\circ} \mathrm{C} \\
30 \mathrm{~s}\end{array}$ & 35 \\
\hline
\end{tabular}

